\title{
Dealing with multivariate missing data in principal component analyses and subsequent model estimation: a two-step worked example using data from the Canadian Longitudinal Study of Aging
}

Anni Hämäläinen ${ }^{1,2 *}$, Paul Mick ${ }^{3}$

1. School of Optometry, Université de Montréal

2. Institute of Environmental Sciences, Jagiellonian University

3. Department of Surgery, University of Saskatchewan

* Corresponding author: anni.m.hamalainen@gmail.com

\section{Abstract}

Missing data can be a significant problem for statistical inference in many disciplines when information is not missing completely at random. In the worst case, it can lead to biased results when participants or subjects with certain characteristics contribute more data than other participants. Multiple imputation methods can be used to alleviate the loss of sample size and correct for this potential bias. Multiple imputation entails filling in the missing data using information from the same and other participants on the variables of interest and potentially other available data that correlate with the variables of interest. The missing data estimates and uncertainty associated with their estimation may then be taken into account in statistical inference from those variables. A complication may arise when using compound variables, such as principal component loadings (PC), which draw on a number of raw variables that themselves have non-overlapping missing data. Here, we propose a sequential multiple imputation approach to facilitate the use of all available data in the raw variables contained in compound variables in a way that conforms to the specifications of the multiple imputation framework. We first use multiple imputation to impute missing data for the subset of raw variables used in a principal component analysis (PCA) and perform the PCA with the imputed data; then, use the factor loadings to calculate PC scores for each individual with complete raw data. Finally, we include these PC scores as part of a global multiple imputation approach to estimate a final statistical model. We demonstrate (including annotated Stata code) the use of this approach by examining which sensory, health, social and cognitive factors explain self-reported sensory difficulties in the Canadian Longitudinal Study of Aging (CLSA) Comprehensive Cohort. The proposed sequential multiple imputation approach allows us to deal with the issue of having large cumulative amount of data that is missing (not completely at random) among a large number of variables, including composite cognitive scores derived from a battery of cognitive tests. We examine the resulting parameter estimates using a range of recommended diagnostic tools to highlight the potential and consequences of the approach to the statistical results. 


\section{Introduction}

Missing data is a problem shared by many disciplines, including epidemiological studies. Incomplete data reduces the sample size and thus the power of analyses. Furthermore, missing data can be a significant problem when information is not missing completely at random, leading to biased results when participants or subjects with certain characteristics contribute more data than other participants. Several approaches have been proposed to alleviate the loss of sample size and correction of this potential bias. Both of these problems can be alleviated via data imputation, which involves estimating values for the missing data points based on values from other participants, and/or information from other, related variables on the same participants. The most sophisticated approaches incorporate both data from the same and other participants on the variables of interest and other available data for the focal participant. This can be accomplished using various multiple imputation methods.

Multiple imputation consists of three phases. First, values are estimated for the missing data to generate a complete data set. This imputation step is repeated multiple times to create a pool of $M$ datasets with slightly varying estimates for the missing data points. Next, each of the $m$ filled-in data sets is analysed using the chosen statistical method (here, linear regression modeling). Finally, the parameter estimates obtained in the analysis phase are pooled to derive results that are adjusted for uncertainty due to the missing data ${ }^{1}$. Thus, in a standard multiple imputation algorithm, imputation and the final statistical analysis are performed sequentially but within the same computer program. This allows for model variance estimates (e.g., standard errors, confidence intervals and p-values) to be adjusted upwards according to the additional variability introduced by including imputed (rather than real) data. The size of the adjustments is proportionate to the variability in the parameter estimates observed for each variable among the $M$ datasets.

One of the most flexible multiple imputation methods is "MICE", Multiple Imputation with Chained Equations, which derives estimates of missing data points simultaneously for all variables of interest with missing data, using a sequence of multivariate regression models ${ }^{2-6}$. An advantage of this approach is the possibility to accommodate different data types from continuous to binomial, and to model each variable with the appropriate error structure to derive correct parameter estimates for different types of data. Estimating the models of interest within the MICE framework permits the use of all available data while correcting the parameter estimates for the uncertainty introduced by the estimated missing data.

A complication of multiple imputation may arise if a researcher wishes to use a compound variable calculated from raw variables in a statistical model, rather than the raw variables themselves. In general, the principal components can only be computed using complete data for the raw variables, potentially generating bias in the compound variable already before imputation if data are not missing completely at random. Using multiple imputation methods when generating derived variables from raw data requires a decision on the stage at which compound variables are calculated:

A.) Missing raw data are imputed in a single step with all relevant variables within the multiple imputation framework and the derived variable (e.g. principal component score) is only then 
computed using the imputed data (as a "passive variable"). However, statistical inference based on variables generated post-imputation might bias the results ${ }^{7}$; and PCA within the multiple imputation framework is not supported by statistical software such as Stata.

B.) Alternatively, the derived variable is first calculated using the raw data, and the imputation of missing data for the derived variable occurs in a subsequent multiple imputation step of all relevant variables.

Most multiple imputation techniques do not accommodate approach $\mathrm{A}$ because the raw data are not included in the final statistical model. This type of approach would not conform to the specifications of multiple imputation algorithms, which require imputation and analysis to be conducted concurrently. Approach B is thus the preferred option in terms of using the imputed data for statistical analyses ${ }^{7}$. However, it is prone to losing excessive information contained in the raw data when compound variables are calculated using multiple raw variables that have non-overlapping missing data. For example, in a principal component analysis (PCA) that aims to generate principal component scores from multiple raw data points, if an individual has missing data on only one (of many) raw variables, none of their data will contribute to the principal component calculations. Only cases with complete data for all of the raw variables contribute to the analysis while information from cases with any missing data are lost.

To generate principal component factor loadings based on all available raw data, yet still utilize standard MICE procedures, we propose a 2-step approach where we:

\section{Compute principal component weighting factors correcting for missing data in the raw}

variables. We use multiple imputation to impute missing data for the subset of raw variables used in the PCA and perform the PCA with the imputed data; then, use the factor loadings to calculate PC scores for each individual with complete raw data. Note that individuals with missing data for any of the raw variables used to generate the principal component scores will have "missing" principal component scores.

2. Use the principal component scores generated in step 1 as part of a global multiple imputation approach to estimate a final statistical model. Multiple imputation is used to impute missing data for all of the independent and dependent variables in the model, including the principal component scores. In this way, we ensure that the variance estimates in the final model adequately adjust for the uncertainty resulting from using imputed data to create the composite (PC) scores.

The purpose of this paper is to use such a 2-step approach to address the issue of having large cumulative amount of missing data (missing at random, but not missing completely at random, see e.g. ${ }^{8}$ ) among a large number of variables in the Canadian Longitudinal Study of Aging (CLSA) Comprehensive Cohort, and creating composite variables from a subset of the raw variables using PCA. We describe this two-step method and the associated diagnostics, building upon an approach suggested in a Stata tutorial ${ }^{1}$, which, in turn, is based on published work on various multiple imputation methods (e.g. ${ }^{7-11}$ ). The detailed methods, results, and conclusions from our analyses using this imputation approach are reported elsewhere ${ }^{12-14}$. 


\section{Data collection and variables of interest}

\section{Research objectives and data}

The ultimate purpose of our research programme was to examine associations among sensory function (behavioral and self-report measures of hearing and vision ability), cognitive function (based on results in a cognitive test battery), and risk factors for age-related decline in sensory and cognitive performance. For illustrative purposes, we show here the results of an analysis where we predicted the likelihood of self-reporting sensory difficulties as a function of behavioral measures of hearing and vision, cognitive performance, and other aspects of the participants' health, socioeconomic, and social profile (for details see ${ }^{14}$ ).

We used data collected from the 30,097 participants of the Canadian Longitudinal Study of Aging (CLSA) Comprehensive Cohort. The CLSA is a prospective longitudinal study that follows participants aged 45-85 at baseline for 20 years. Additional information on the study is available from e.g. ${ }^{15-18}$. The first wave of data was collected in 2012-2015 and released to researchers in 2017, thus the analyses reported here are cross-sectional.

We applied inverse probability weights provided by CLSA (https://www.clsa-elcv.ca/doc/1041) to adjust for population representation of the participants based on sex, age, and province of residence.

\section{Cognitive variables of interest}

We performed a principal component analysis to determine if we could create composite cognitive scores from the results of five different cognitive tests. The tests produced a total of seven different measures of cognitive function that were retained for analyses (Table 1). The tests and measures included:

\section{- Executive function.}

- Controlled Oral Word Association Test. Participant is asked to generate as many words as possible that begin with a given letter in 60s ( 3 trials, letters $F, A, S$ ). Test score $=$ total number of words.

- Animal fluency test. Participant is asked to generate as many animals as possible in $60 \mathrm{~s}$. Test score $=$ total number of different animals named.

- Mental alternation test. Participant is asked to generate the numbers 1-26 and the letters of the alphabet, alternating between each $(1-A, 2-B, 3-C, \ldots)$. Test score $=$ number of correct alternations.

- Stroop test Victoria version. Participant is asked to quickly name the color of a visual cue (dots or words on cards). Two variables were retained for analyses: Interference score (total time taken to name the ink colors, rather than the color word printed on a card) and Stroop ratio (ratio of Interference score to Control task score, naming the color of printed dots.

- Memory:

- Rey Auditory Verbal Learning Test. Participants listen to a recorded list of 15 words once, and are asked to repeat the words back immediately and again after $5 \mathrm{~min}$. Two variables 
were retained for analyses: Delayed recall (\# words correctly recalled $5 \mathrm{~min}$ after hearing the recording) and Retention (ratio of delayed to immediate recall).

Details on the choice and administration of the cognitive tests are provided in ${ }^{15,19}$, and further details on the method for deriving the cognitive scores through principal component analyses are provided below and in ${ }^{13}$.

\section{Sensory variables of interest}

We used previously described behavioral measures of hearing and vision ${ }^{20,21}$. Vision was measured as the better-seeing eye pinhole-corrected visual acuity (VA; reported in logMAR). Hearing was measured as the better-hearing ear mid-range pure-tone average (BPTA; reported in $\mathrm{dB} \mathrm{HL}$ ) across four frequencies: 1000, 2000, 3000 and $4000 \mathrm{kHz}$. Additional information on these can be found in e.g. ${ }^{20,21}$. Additionally, we included a number of other variables associated with the sensory data collected via testing on site or through self-report in participant interviews. These are listed in Table $\mathbf{2}$ and include information on the worse-seeing eye and ear, use of vision or hearing aids, and self-reported vision difficulties (VD) and hearing difficulties (HD). We generated a new "passive" categorical variable for Dual sensory difficulty using imputed variables indicating hearing and vision impairments (DSD; impairment of both vision and hearing, vs. impairment in neither or only one sense).

\section{Other variables of interest}

In addition to associations between and among sensory and cognitive variables, we examined the associations of these variables to socioeconomic, demographic and health status, as well as indicators of social participation (Table 2). In addition to variables included in some of the analyses, we also included in the multiple imputation approach some auxiliary variables that were not used in the eventual regression analyses but are correlated with imputed variables of interest and could, therefore, improve the computation of imputed values for those variables. All of these variables were included in the MICE approach (Step 2).

\section{Description of missing data}

Data were missing for $1.4-8.8 \%$ of the participants for the cognitive test results (Table 1 ) and a moderate amount of data was missing for some of the other variables (Table 2). Combined with the large number of variables included in our models, the cumulative number of observations excluded from complete case analyses came to $>50 \%$ for some models because of non-overlapping missing variables. We assume that the data are "missing at random" ("MAR"), i.e. the probability that data are missing depends, at least in part, on other, observed data. This conclusion was supported by exploratory analyses of missingness patterns. For example, exploratory analyses suggested that those with missing data on income, hearing and cognition may be more likely to be older and less healthy, leading to misrepresentation of the sample when using complete-case analyses ( ${ }^{22}$ and literature therein). 
Table 1. Missing data in cognitive variables used in the computation of the principal components.

\begin{tabular}{lllll} 
Variable & Abbreviation & $\begin{array}{l}\text { N with } \\
\text { complete data }\end{array}$ & $\begin{array}{l}\text { N with } \\
\text { missing data }\end{array}$ & \%missing \\
\hline Rey Auditory Verbal Learning Test, Delayed recall & REY2 & 29,026 & 1,071 & 3.69 \\
Rey Auditory Verbal Learning Test, Recall ratio & REYr & 28,688 & 1,409 & 4.91 \\
Stroop test, Interference task & STP & 29,671 & 426 & 1.44 \\
Stroop ratio, Stroop ratio & STPr & 29,659 & 438 & 1.48 \\
Mental alternation test & MAT & 27,666 & 2,431 & 8.79 \\
Controlled Oral Word Association Test & FAS & 28,978 & 1,119 & 3.86 \\
Animal fluency test & AFT & 28,481 & 1,616 & 5.67
\end{tabular}

All variables were treated as continuous, with a Gaussian error distribution. 
Table 2. Missing data. Total sample size for all variables after imputation: $\mathrm{N}=30097$. Variables with more than $10 \%$ missing data in bold.

\begin{tabular}{|c|c|c|c|c|}
\hline & $\begin{array}{l}\mathrm{N} \text { with } \\
\text { complete data }\end{array}$ & $\begin{array}{l}\mathrm{N} \text { missing } \\
\text { (imputed) }\end{array}$ & $\begin{array}{l}\% \\
\text { missing }\end{array}$ & $\begin{array}{l}\text { Error } \\
\text { distribution }\end{array}$ \\
\hline \multicolumn{5}{|l|}{$\begin{array}{l}\text { Variables of interest (included in } \\
\text { estimation models) }\end{array}$} \\
\hline Age ( $45-85$ years) & 30,097 & 0 & 0.00 & Gaussian $^{1}$ \\
\hline Sex & 30,097 & 0 & 0.00 & Binomial ${ }^{1}$ \\
\hline BPTA (mid-range, 10 dB HL) & 29,062 & 1,035 & 3.44 & Gaussian \\
\hline Pinhole VA logMAR & 29,385 & 712 & 2.37 & Gaussian \\
\hline Self-report hearing difficulty (HD) & 30,069 & 28 & 0.09 & Binomial \\
\hline Self-report vision difficulty (VD) & 30,078 & 19 & 0.06 & Binomial \\
\hline Ear asymmetry & 28,192 & 1,905 & 6.33 & Gaussian \\
\hline Eye asymmetry & 29,172 & 925 & 3.07 & Gaussian \\
\hline Better-eye refractive error & 26,472 & 3,625 & 12.04 & Gaussian \\
\hline Trouble hearing in noise & 30,024 & 73 & 0.24 & Binomial \\
\hline Vision pathology diagnosis & 25,515 & 4,582 & 15.22 & Binomial \\
\hline Visited eye care professional & 28,705 & 1,392 & 4.63 & Binomial \\
\hline Wore prescribed vision correction for test & 30,096 & 1 & $<0.01$ & Multinomial \\
\hline Vision aid use & 30,092 & 5 & 0.02 & Binomial \\
\hline Hearing aid use & 30,095 & 2 & 0.01 & Binomial \\
\hline PC1 (Executive function) ${ }^{2}$ & 25,051 & 5,046 & 16.77 & Gaussian \\
\hline PC2 (Memory) ${ }^{2}$ & 25,051 & 5,046 & 16.77 & Gaussian \\
\hline Multimorbidity & 28,166 & 1,931 & 6.42 & Poisson \\
\hline Cultural background & 30,081 & 16 & 0.05 & Binomial \\
\hline Education & 30,022 & 75 & 0.25 & Ordinate \\
\hline Income & 28,156 & 1,941 & 6.45 & Ordinate \\
\hline Life space index & 30,044 & 53 & 0.18 & Gaussian \\
\hline Social participation types & 30,034 & 63 & 0.21 & Gaussian \\
\hline Social network index & 29,982 & 115 & 0.38 & Gaussian \\
\hline Social support availability & 30,007 & 90 & 0.30 & Gaussian \\
\hline Social participation frequency & 30,025 & 72 & 0.24 & Ordinate \\
\hline Retirement status & 29,987 & 110 & 0.37 & Ordinate \\
\hline Driving status & 27,561 & 2,536 & 8.43 & Binomial \\
\hline Lives alone & 30,054 & 43 & 0.14 & Binomial \\
\hline Feeling lonely & 29,976 & 121 & 0.40 & Binomial \\
\hline \multicolumn{5}{|l|}{$\begin{array}{l}\text { Auxiliary variables used to improve } \\
\text { imputations }\end{array}$} \\
\hline BPTA “Low frequencies” & 29,088 & 1,009 & 3.35 & Gaussian \\
\hline BPTA “Speech frequencies" & 29,060 & 1,037 & 3.45 & Gaussian \\
\hline BPTA “High frequencies" & 29,016 & 1,081 & 3.59 & Gaussian \\
\hline Binocular habitual visual acuity & 29,362 & 735 & 2.44 & Gaussian \\
\hline Stroop test baseline time ("dot time") & 29,689 & 408 & 1.36 & Gaussian \\
\hline
\end{tabular}


1. No missing data, thus the variables were used as fixed, auxiliary variables for the purposes of imputation.

2. The principal components were derived from raw data collected from five cognitive tests. These variables were imputed separately in Step 1 and the derived variables were included in the universal MICE-step.

3. Variable associated with dual sensory difficulties was generated as a "passive variable", computed using the imputed data for HD and VD, separately for each of the 30 datasets.

\section{Multiple imputation approach}

\section{Two-step imputation approach overview}

In the following sections we provide a more detailed description of the two-step methodology summarized above (see schematic in Figure 1). We used a two-step multiple imputation approach to maximize the use of available data collected from the participants on a large number of variables. Our analyses required deriving a principal component score of cognitive functioning to assess cognitive performance as a risk factor for self-reported sensory difficulties using multiple regression models. Thus, in Step 1, we used multivariate normal regression imputation to generate a covariance matrix for principal component analysis of the cognitive variables. For this, we derived principal component scores via multivariate normal regression (mvn) imputation using all available cognitive test results. In Step 2, we imputed missing data in these principal component scores and all other variables of interest using a chained-equations multiple imputation (MICE) ( $M=30$ imputed datasets) to derive estimates for the missing values in the composite (principal component) cognitive scores and other variables in the model, and used these values in the multiple imputation framework to estimate all multiple regression models.

This two-step imputation approach was chosen because 1) the cumulative proportion of missing data for the cognitive tests was relatively high (approx. 17\%) although any one participant rarely lacked data for more than one test; and 2) it is recommended that the "final" form of the variables of interest (i.e., those variables included in the final regression model) be included in the multiple imputation process (here: principal component-scores rather than the raw data; see e.g. ${ }^{1,7}$ ).

All analyses were conducted in Stata version 15.1. The annotated Stata code is provided in the Appendix. 


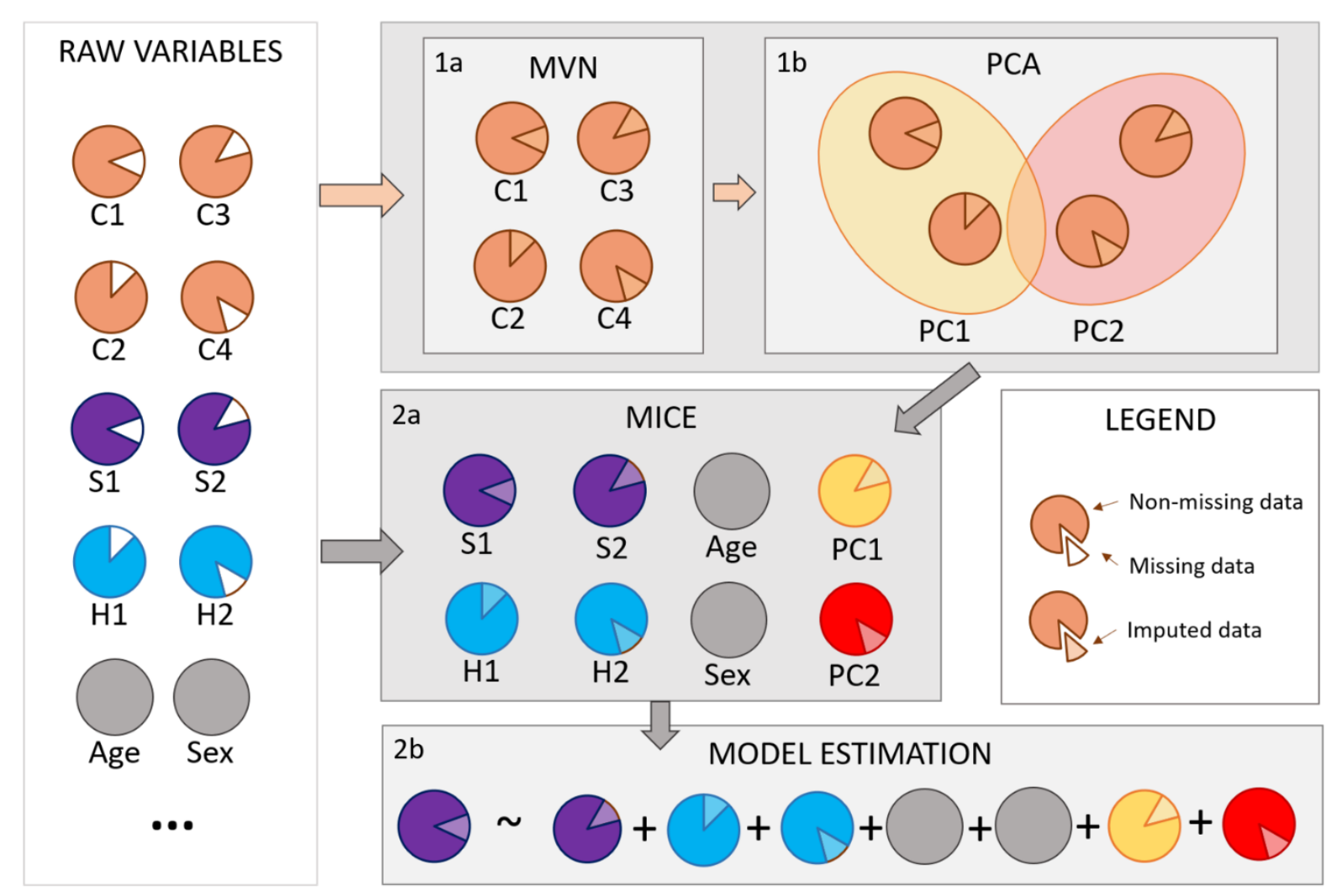

Figure 1: A schematic of the two-step imputation approach developed in this paper. The pie charts represent different variables (C1-4: example cognitive variables; S1-2 example sensory variables; H1-2: example health variables), each with some proportion of missing data that is filled in using multiple imputation approaches. In the first imputation step, 1a) cognitive data are imputed using multivariate normal regression imputation (MVN) and $1 \mathrm{~b}$ ) principal component analysis (PCA) is used to derive cognitive principal component (PC) scores. In the second step, 2a) the PC-scores are included in a global chained-equations multiple imputation (MICE) to fill in missing data in all variables and finally, $2 \mathrm{~b}$ ) the imputed data are used to estimate a statistical model. Additionally, age and sex, with no missing data, were included in the second imputation step as fixed, auxiliary variables. 


\section{Step 1: Principal component analysis of cognitive variables with multiple imputation}

We derived an imputed correlation matrix of the seven cognitive test results using a maximum likelihood estimation with an expectation-maximization (EM) algorithm in Stata's mi framework (https://stats.idre.ucla.edu/stata/faq/how-can-i-do-factor-analysis-with-missing-data-in-stata/; ${ }^{8-11}$. As recommended in the above tutorial, we assumed an arbitrary sample size for this estimation as the $\mathrm{N}$ of non-missing observations for the variable with the largest proportion of missing data - in this case, the mental alternation test $(\mathrm{N}=27666)$. This imputed correlation matrix was then used to generate the component "weights" for each variable included in the PCA and used to compute principal component scores.

\section{Principal component scores}

After computing the principal components (PC), we calculated the PC scores for those individuals who had complete cognitive data available (no missing for any of the 7 raw cognitive variables), i.e. for a sample size of $\mathrm{N}=25051$. The scores used for the PC estimation are thus based on the imputed correlation matrix rather than the raw data.

Rotated loadings estimated using the EM algorithm (shown in Table 3) indicated that the first axis captures mostly variance in the executive function test results (high loadings of animal fluency test, controlled oral word association test, mental alternation test, Stroop test and Stroop ratio; Eigenvalue = 2.7, explained $34.3 \%$ of the variation in the cognitive data) and variables associated with memory loaded strongly on the second axis (Rey auditory-verbal learning test and Rey ratio; Eigenvalue $=1.4,25.2 \%$ of total variance explained). The combined variance explained by these two components was $59.5 \%$. Thus, we extracted the scores for PC1, taken to represent Executive function, and PC2, taken to represent Memory. The weights for PC1 and PC2 derived from the EM-algorithm were used to calculate PC1 and PC2 scores for those participants who had existing data for all 7 test results. Those participants with missing data for any of the 7 variables (Table 1) had missing data for both PC1 and PC2. In the final statistical model, we imputed the missing data in these principal components ( $N=5046$ participants missing) using chained-equations multiple imputation (see Step 2).

Table 3: PCA-scoring coefficients for Kaiser-adjusted orthogonal varimax rotation. Loadings and eigenvalues of the two extracted components (PC1=executive function; PC2=memory) in bold.

\begin{tabular}{l|rrrrrrr} 
Variable & Comp1 & \multicolumn{1}{c}{ Comp2 } & \multicolumn{1}{c}{ Comp3 } & \multicolumn{1}{c}{ Comp4 } & \multicolumn{1}{c}{ Comp5 } & \multicolumn{1}{c}{ Comp6 } & \multicolumn{1}{c}{ Comp7 } \\
\hline FAS & $\mathbf{0 . 4 2 2}$ & 0.036 & 0.391 & -0.330 & 0.743 & 0.062 & -0.058 \\
AFT & $\mathbf{0 . 4 0 2}$ & 0.122 & 0.337 & -0.501 & -0.653 & 0.165 & -0.071 \\
MAT & $\mathbf{0 . 4 4 9}$ & 0.014 & 0.312 & 0.782 & -0.093 & 0.282 & 0.034 \\
Stroop & $\mathbf{- 0 . 5 5 1}$ & 0.034 & 0.325 & -0.080 & 0.060 & 0.733 & 0.204 \\
Stroop ratio & $\mathbf{- 0 . 3 8 1}$ & 0.173 & 0.698 & 0.132 & -0.066 & -0.545 & -0.137 \\
Rey delayed & 0.084 & $\mathbf{0 . 6 6 9}$ & -0.082 & -0.007 & 0.028 & -0.136 & 0.721 \\
Rey ratio & -0.059 & $\mathbf{0 . 7 1 1}$ & -0.193 & 0.065 & 0.064 & 0.188 & -0.641 \\
\hline Eigenvalue & $\mathbf{2 . 4}$ & $\mathbf{1 . 8}$ & & & & & \\
\hline \% Variance explained & $\mathbf{3 4 . 3}$ & $\mathbf{2 5 . 2}$ & & & & & \\
\hline
\end{tabular}




\section{Step 2: Chained-equations multiple imputation method}

We used a chained-equations multiple imputation approach ("MICE") to make use of non-missing data to estimate the missing values for all variables with iterative multivariate models. For general information on the method, see $2,4,5$ and for detailed advice on the implementation of the method in Stata, see ${ }^{1}$ https://stats.idre.ucla.edu/stata/seminars/mi in stata pt1 new/. Briefly, MICE is an iterative multivariate approach in which the missing data for each variable are imputed in turn, starting with the variable with the least missing data. The imputations are done through regressions of each variable against all other variables in the imputation run, such that different data distributions can be modeled using the appropriate error structure (see "Error distribution" column in Table 2). Thus, the missing values for each of the variables included in the imputation run are predicted using all other variables in the same run. E.g. missing values for Income were derived from a model that used Income as a dependent variable, and all other variables in Table $\mathbf{2}$ as independent variables. This iterative process is used to generate a number of imputed datasets, which are then used for follow-up analyses (here: deriving parameter estimates from multiple regression models).

The error associated with the estimation of the missing values is captured in the slight differences in estimates among imputed datasets. The slight differences among the datasets are used during model estimation to adjust the standard errors for each of the variables that had any missing data. This is done by adjusting (increasing) the standard errors around the estimates, and these upscaled standard errors are then used in the calculation of the statistical significance of the associations between variables. All estimates reported in downstream analyses are based on these imputed and error-adjusted estimates.

We used MICE to derive estimates for the missing values in all variables of interest. In addition to the variables used as independent and dependent variables in our multiple regression models, we included auxiliary variables (as long as the additional variables did not prevent convergence of the imputations) that were not included in the models of self-reported sensory difficulties, but could improve the imputed estimates for variables of interest. To this end, we chose auxiliary variables that were correlated with the variables of interest, and/or could provide information about the true values of the missing data, or about the likelihood of missingness for a variable. The variables of interest (used in multiple regression models of self-reported sensory difficulties) and included auxiliary variables (not used in models) and the missing data for each of them are shown in Table $\mathbf{2}$.

We generated $M=30$ imputed datasets, exceeding the recent recommendation for minimum $M=20$ to reduce sampling error due to imputations ${ }^{22}$. We used the default burn-in period of 10 iterations per dataset (5-20 recommended, e.g. ${ }^{23}$ ), thus resulting in a total of 300 iterations to obtain the 30 datasets. After completing the imputations, the resulting 30 complete datasets (with complete data for all variables for all 30,097 rows (i.e. individuals) in each of the datasets) were used to estimate the models for the dependent variables of interest using Rubin's rules ${ }^{24}$; here, the logistic regression models of HD, VD and DSD. 


\section{Diagnostics and sensitivity analyses}

We used the imputed data within the multiple imputation framework (Stata mi) to estimate all multiple regression models. The benefit of using this framework is that it incorporates uncertainty from the multiple imputation in the statistical estimation of model parameters by adjusting their associated standard errors. For the interpretation of the results, it is necessary to assess the effects of this uncertainty on the statistical results. To evaluate the performance of the multiple-imputed data (i.e. adjusting for uncertainty from missing data), we performed various diagnostics as recommended by e.g. 22,25,26. Additionally, we performed sensitivity analyses by comparing the results of our imputed data or models to the same analyses using complete cases. The details of the diagnostics for each imputation step are described below.

\section{Step 1: Expectation maximization (EM) diagnostics}

The EM algorithm was declared by the analytic output to converge in 7 iterations (out of the default of 1000 used in the imputation run). To confirm this to be the case, we assessed convergence by repeating the imputation of cognitive raw variables to extract Markov Chain Monte Carlo (MCMC) estimates for a burn in period of 1000 (the equivalent of 10 imputations) as recommended by Stata documentation on multivariate normal regression methodology (mi mvn; https://www.stata.com/manuals13/mimiimputemvn.pdf). An examination of trace plots of the means (Figure 2)), variances and covariances of all cognitive variables, as well as trace plots and autocorrelation plots of the "worst linear function" (Figure 3) revealed no patterns, confirming that convergence could be achieved with much fewer iterations than the default (1000) used ${ }^{11}$. Additionally, a sensitivity assessment confirmed that the PC ranges and loadings were qualitatively similar for the imputed estimates as for a PCA using complete cases ( $N=25051)$ without the EM-approach. The same principal components were suggested by both the imputed and complete-case data. This confirms that the imputation did not alter the correlation patterns among the raw cognitive variables. 

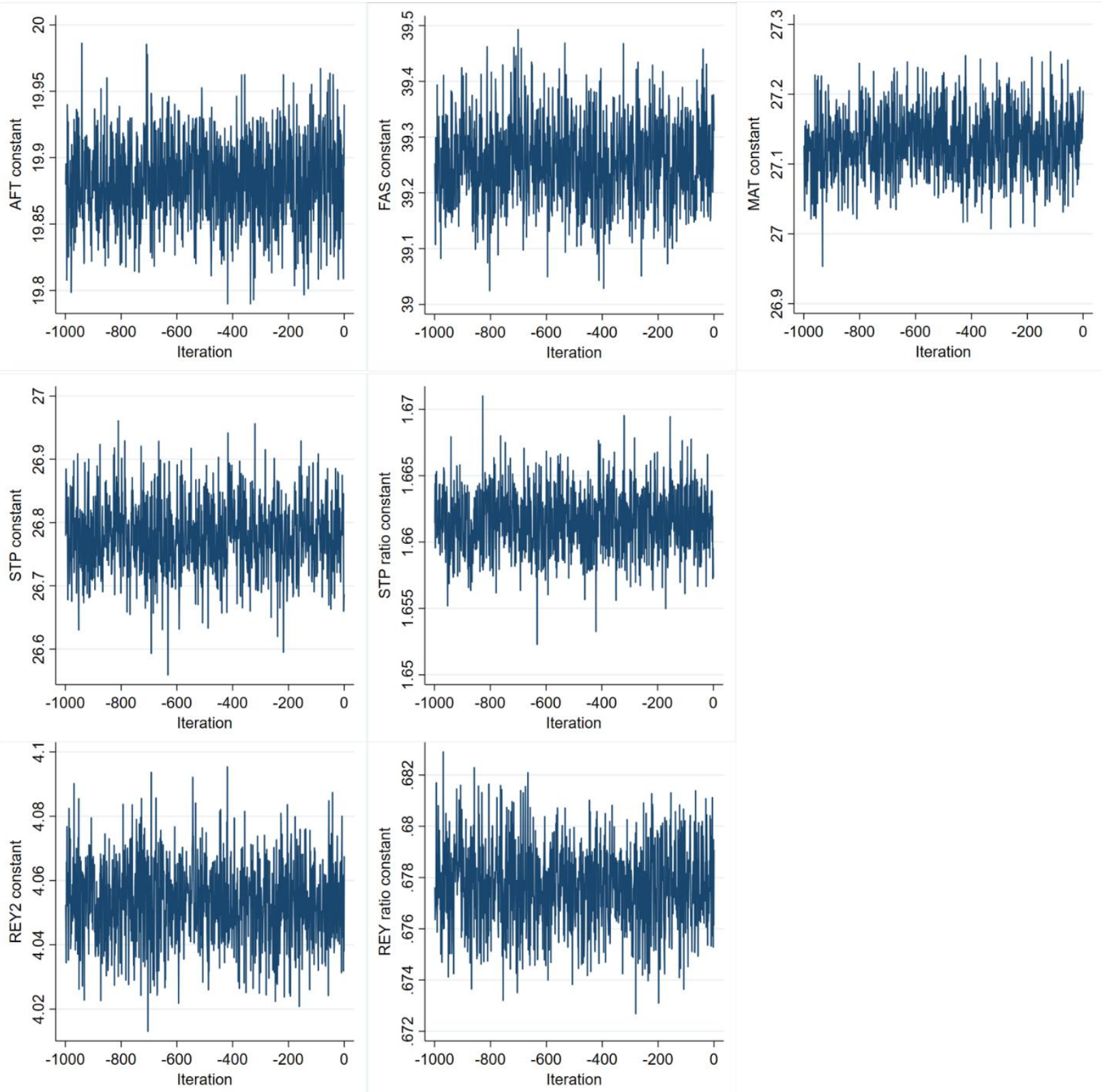

Figure 2: Diagnostic trace plots of all cognitive test results included in the EM-matrix prior to the PCA. For the abbreviations, see Table 1. 

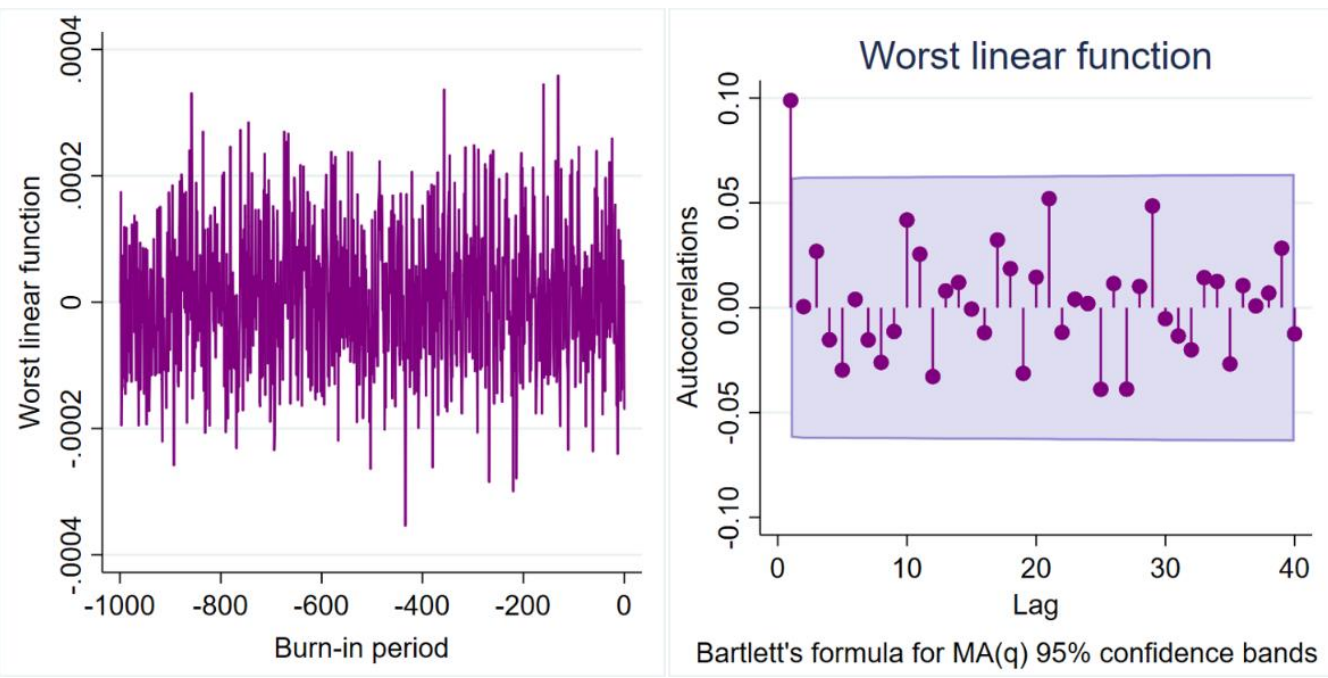

Figure 3: Diagnostic trace plot and autocorrelation plot using the "worst linear function" of the maximum likelihood estimation of the covariance matrix of imputed cognitive variables (Step 1). The absence of pattern in the trace plot, and the near-instantaneous reaching of zero in the autocorrelation plot confirm independence of imputed estimates.

\section{Step 2: MICE diagnostics}

We used diagnostic plots to check the variables with the most missing data for consistency relative to observed data, and examined the trace plots (Figures 4-5) and autocorrelation plots (Figure 6) to assess convergence, and examined the distributions of the imputed and observed (complete-case) data to assess the significance of the imputations on the data distributions (Figure 7). Furthermore, we assessed the relative efficiencies, within-and between-data set variances and inflation of standard errors to assess the adequacy of the imputations and their effects on the model outcomes. We also examined the Fraction of Missing Information (FMI; proportion of the total sampling variance that is due to missing data); the Relative Increase in Variance (RVI; proportion of increase in total sampling variance due to missing information); the Relative Efficiency (RE; estimated efficiency of the imputation, relative to performing an infinite number of imputations), as well as the between-imputation and the withinimputation variance estimates for all variables used in the models. For further description and justification of these diagnostics, see e.g. ${ }^{1}$.

Unsurprisingly, the unimputed and imputed data had slightly different distributions for many of the variables that had a substantial amount of missing data (Figure 7). This is expected when the data are not missing completely at random. The increase in standard errors due to missing data ranged from 621\% for PC1 and 7-23\% for PC2. However, the imputations produced sufficiently consistent estimates that the estimated relative efficiencies (RE) were $\geq 0.99$ for all variables in our final models (Tables 4-6), indicating that $M=30$ was sufficient for the amount of missing information. Overall, these results and other diagnostics (e.g. Figures 4-5) indicate that the imputations of even the variables with the highest proportion of missing data produced reliable results. Nevertheless, the standard errors of those variables with more than $10 \%$ missing data (PC1, PC2, vision disease diagnosis, refractive error) were 
increased by up to $20 \%$ (Table 5; vision disease diagnosis variable in VD model). Thus, the standard errors of these predictor variables are corrected for larger potential sampling error, and their statistical significance is adjusted downwards accordingly to reflect a higher uncertainty in the estimation.

\section{Complete-case analyses}

Finally, we compared the parameter estimated from the multiple imputation approach (Table 7) to a complete-case analysis (Table 8) using full models for $\mathrm{HD}$ (complete cases $\mathrm{N}=17,802), \mathrm{VD}(\mathrm{N}=11,610$ ) and DSD $(N=11,292)$. The variable estimates and main conclusions drawn from complete-case analyses are qualitatively similar to the models using imputed data. Based on a comparison of standard errors (SE) of the complete-case and multiple-imputation approaches, the added data counteracts the inflation of SE despite increases in SE due to multiple imputation. Thus, many variables whose estimates did not reach statistical significance $(P \geq 0.05)$ in the complete-case model became statistically significant in the imputation model. These included (among others) multimorbidity and vision asymmetry on DSD; and social network index on HD. On the other hand, owing to the difference in sample size and partially nonrandom missingness, a few variables that were statistically significant in the complete-case models were not significant in the imputed models. These included the effect of social participation on DSD; the effect of memory (PC2) on HD, and the interaction effect of age with visual acuity on VD. 

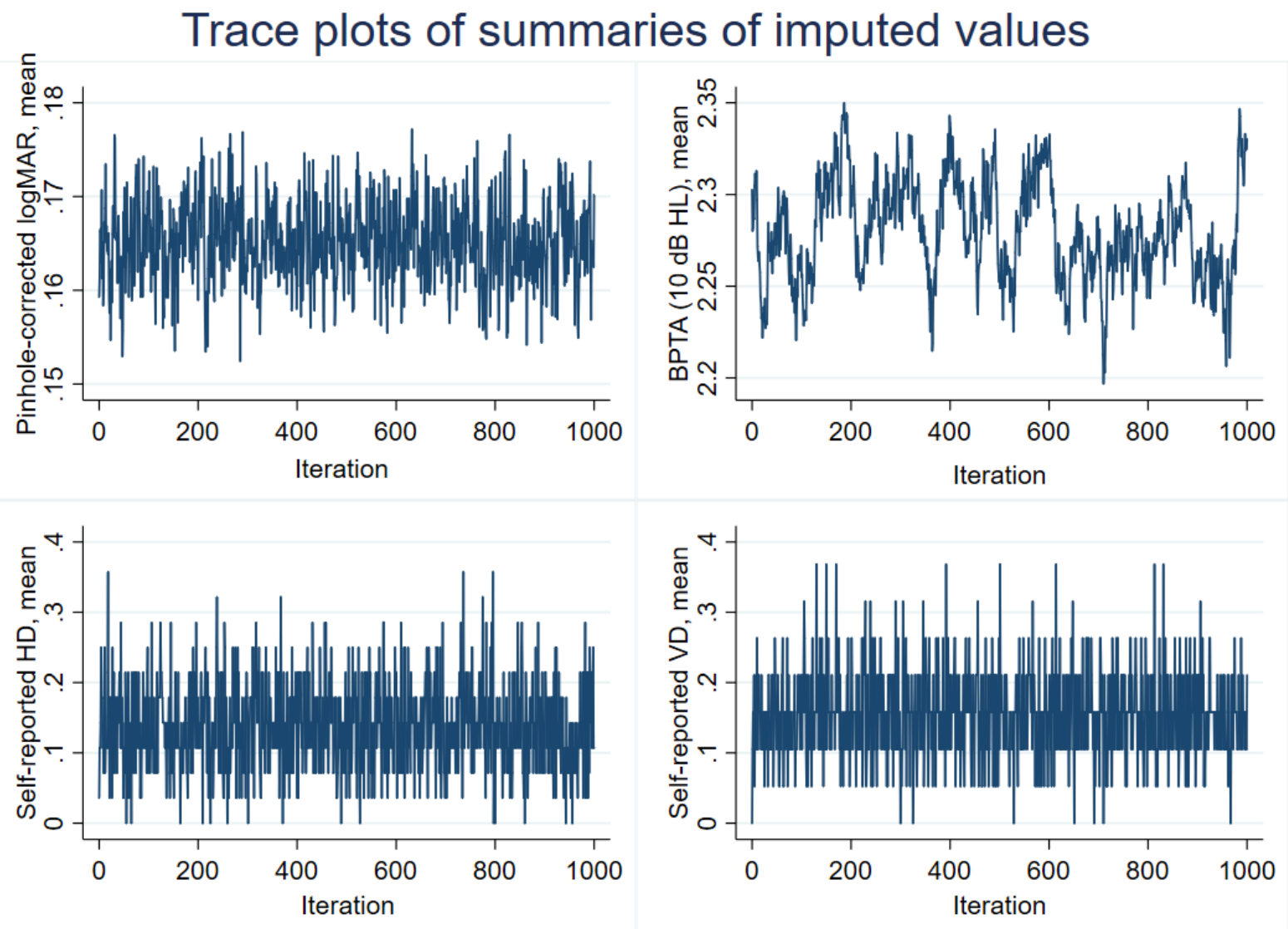

Figure 4: Example trace plots of imputed values for behavioral and self-reported vision and hearing measures over 1000 iterations using MICE (Step 2). The absence of clear patterns suggests adequate mixing of the sample, sufficient burn-in period, and convergence. 


\section{Trace plots of summaries of imputed values}
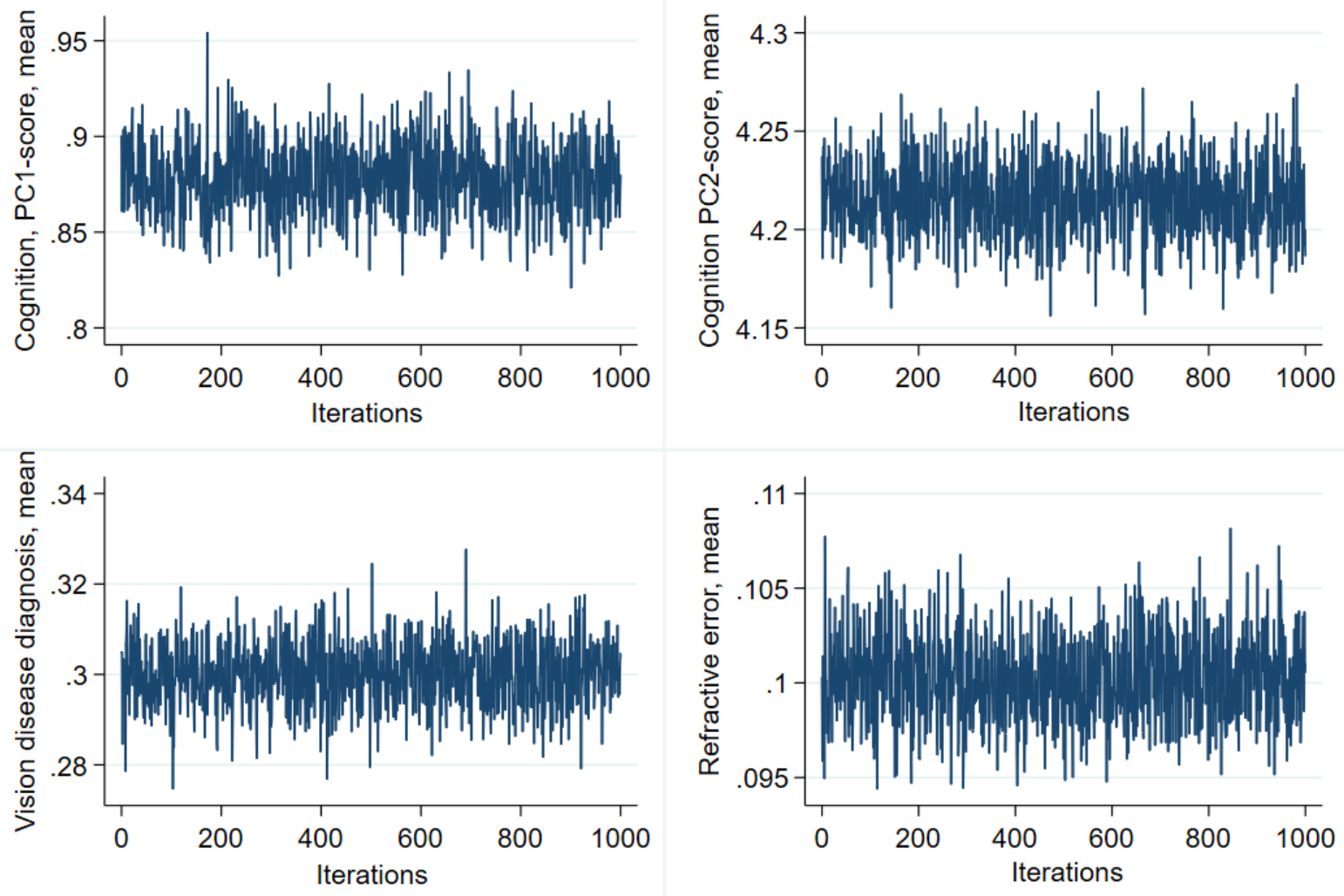

Figure 5: Example trace plots of imputed values (MICE, Step 2) for variables with the largest proportion of missing data: Cognition scores PC1 and PC2, Vision disease diagnosis, and Better-eye refractive error, over 1000 iterations. The absence of clear patterns suggests adequate mixing of the sample, burn-in period, and convergence. 
Autocorrelation plots
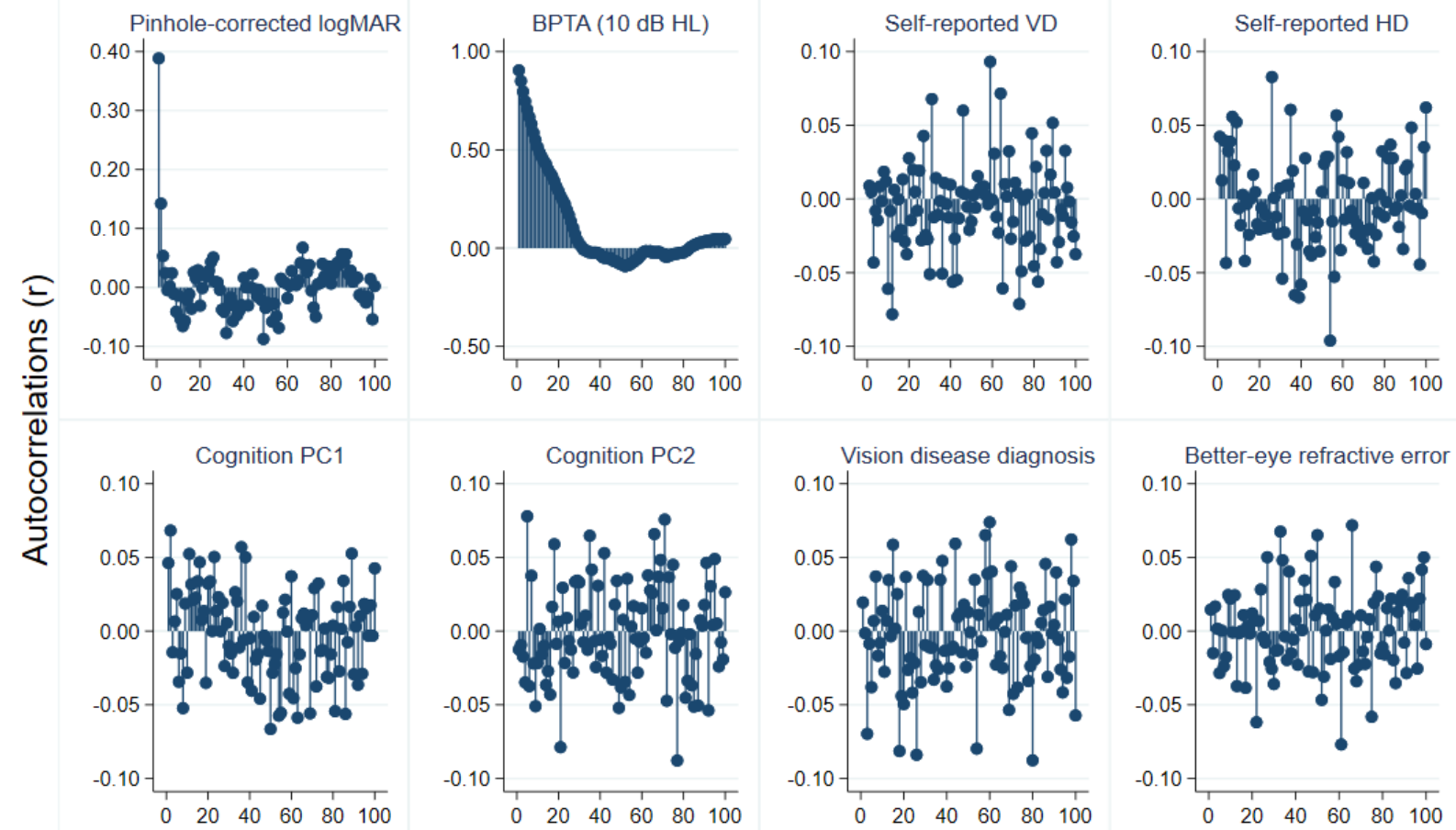

Lag

Figure 6: Example autocorrelation plots for behavioral and self-reported vision and hearing measures, Cognition scores PC1 and PC2, Vision disease diagnosis, and Better-eye refractive error. As $r=0$ is in all cases crossed relatively early (latest with approx. 25 iterations for BPTA), the degree of correlation between values in adjacent imputed datasets is acceptably low. 

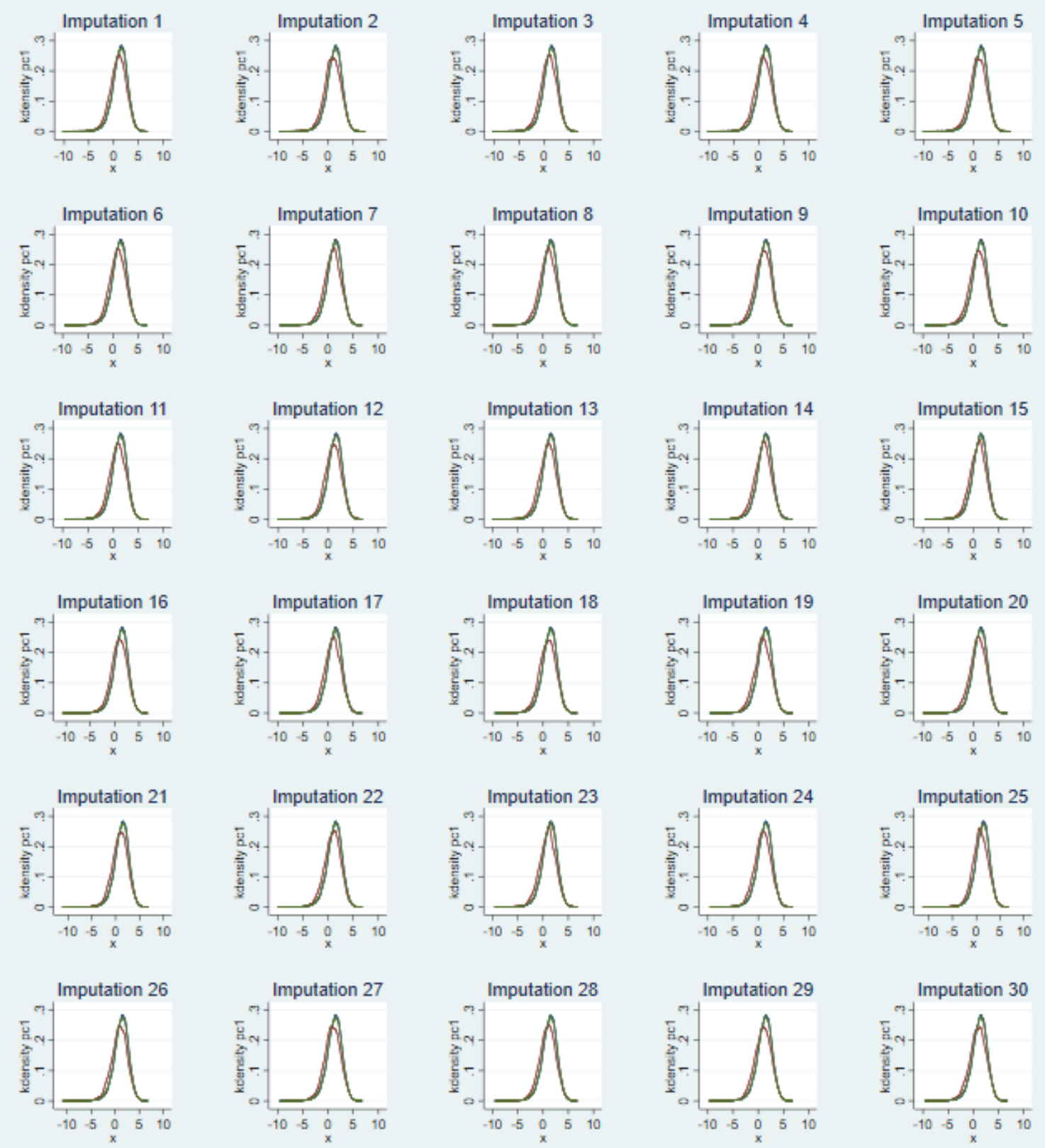

Observed Imputed Completed

Figure 7: Example kernel density diagnostic plots for one of the variables with most missing data, PC1. Shown are the data distributions using original, unimputed data ("Observed"), the imputed data ("Imputed", i.e. estimates generated where data were missing), and the resulting completed datasets ("Observed" + "Imputed") for each of the $M=30$ imputed datasets. Note that the "Observed" data overlap almost completely with the "Completed" data, making the lines invisible and indicating that, 
even though the distribution of the imputed data differ somewhat from the original distribution, the effect of the imputations on the final data distribution is almost imperceptible.

Table 4: Imputation diagnostics for self-reported HD model. RVI (Relative Increase in Variance), FMI (Fraction of Missing Information), RE (Relative Efficiency), as well as the between imputation and the within imputation variance. In bold, $\mathrm{RVI}$ and $\mathrm{FMI}>0.1$, and $\mathrm{SE}$ increase of $>10 \%$.

\begin{tabular}{|c|c|c|c|c|c|c|c|c|}
\hline \multicolumn{9}{|c|}{ Imputation variance } \\
\hline & & Within & Between & Total & RVI & FMI & $\begin{array}{l}\text { Relative } \\
\text { efficiency }\end{array}$ & $\begin{array}{l}\text { \% } \\
\text { increase } \\
\text { in SE }\end{array}$ \\
\hline Age & Years & 0.000 & 0.000 & 0.000 & 0.012 & 0.012 & 1.000 & 0.590 \\
\hline Sex & Male & 0.003 & 0.000 & 0.003 & 0.014 & 0.014 & 1.000 & 0.680 \\
\hline $\begin{array}{l}\text { Cultural } \\
\text { background }\end{array}$ & White & 0.012 & 0.000 & 0.013 & 0.006 & 0.006 & 1.000 & 0.310 \\
\hline \multirow[t]{4}{*}{ Education } & Post-secondary degree & & & & & & & \\
\hline & Some post-secondary education & 0.008 & 0.000 & 0.008 & 0.016 & 0.016 & 0.999 & 0.810 \\
\hline & Secondary school graduate & 0.007 & 0.000 & 0.007 & 0.017 & 0.016 & 0.999 & 0.830 \\
\hline & $\begin{array}{l}\text { Less than secondary school } \\
\text { graduation }\end{array}$ & 0.010 & 0.000 & 0.010 & 0.021 & 0.020 & 0.999 & 1.040 \\
\hline \multirow[t]{5}{*}{$\begin{array}{l}\text { Household } \\
\text { income }\end{array}$} & $>=\$ 150,000$ & & & & & & & \\
\hline & $\$ 100,000-149,999$ & 0.008 & 0.000 & 0.008 & 0.057 & 0.054 & 0.998 & 2.790 \\
\hline & $\$ 50,000-99,999$ & 0.006 & 0.000 & 0.007 & 0.048 & 0.046 & 0.998 & 2.380 \\
\hline & $\$ 20,000-49,999$ & 0.008 & 0.001 & 0.009 & 0.065 & 0.061 & 0.998 & 3.190 \\
\hline & $<\$ 20000$ & 0.018 & 0.001 & 0.019 & 0.080 & 0.075 & 0.998 & 3.950 \\
\hline \multicolumn{9}{|l|}{ Behavioral } \\
\hline \multirow[t]{2}{*}{ threshold } & & 0.015 & 0.000 & 0.015 & 0.017 & 0.017 & 0.999 & 0.860 \\
\hline & BPTA * age & 0.000 & 0.000 & 0.000 & 0.014 & 0.014 & 1.000 & 0.710 \\
\hline Hearing & PTA difference between ears & & & & & & & \\
\hline asymmetry & (/10dB HL) & 0.001 & 0.000 & 0.001 & 0.082 & 0.076 & 0.997 & 4.010 \\
\hline $\begin{array}{l}\text { Hearing device } \\
\text { user }\end{array}$ & Yes & 0.008 & 0.000 & 0.009 & 0.011 & 0.011 & 1.000 & 0.560 \\
\hline $\begin{array}{l}\text { Trouble hearing } \\
\text { in noise }\end{array}$ & Yes & 0.003 & 0.000 & 0.003 & 0.004 & 0.004 & 1.000 & 0.200 \\
\hline $\begin{array}{l}\text { Behavioral visual } \\
\text { acuity }\end{array}$ & Pinhole-corrected logMAR & 0.031 & 0.001 & 0.032 & 0.021 & 0.021 & 0.999 & 1.060 \\
\hline $\begin{array}{l}\text { Self-reported } \\
\text { vision }\end{array}$ & Fair-Poor vision & 0.006 & 0.000 & 0.006 & 0.006 & 0.006 & 1.000 & 0.320 \\
\hline Multimorbidity & \#chronic conditions & 0.000 & 0.000 & 0.000 & 0.065 & 0.062 & 0.998 & 3.210 \\
\hline \multirow[t]{2}{*}{ Cognition } & Executive function (PC1 score) & 0.000 & 0.000 & 0.000 & 0.152 & 0.133 & 0.996 & 7.350 \\
\hline & Memory (PC2 score) & 0.000 & 0.000 & 0.000 & 0.312 & 0.241 & 0.992 & 14.530 \\
\hline \multirow[t]{3}{*}{$\begin{array}{l}\text { Retirement } \\
\text { status }\end{array}$} & Retired & & & & & & & \\
\hline & partly retired & 0.006 & 0.000 & 0.006 & 0.012 & 0.012 & 1.000 & 0.590 \\
\hline & not retired & 0.005 & 0.000 & 0.005 & 0.011 & 0.011 & 1.000 & 0.540 \\
\hline
\end{tabular}




\begin{tabular}{|c|c|c|c|c|c|c|c|c|}
\hline Driving status & Drives at least occasionally & 0.008 & 0.001 & 0.009 & 0.097 & 0.089 & 0.997 & 4.760 \\
\hline Living situation & $\begin{array}{l}\text { Lives alone (ref. lives with } \\
\text { others) }\end{array}$ & 0.004 & 0.000 & 0.004 & 0.018 & 0.018 & 0.999 & 0.890 \\
\hline Life space index & Composite score & 0.000 & 0.000 & 0.000 & 0.011 & 0.011 & 1.000 & 0.570 \\
\hline $\begin{array}{l}\text { Social } \\
\text { participation }\end{array}$ & Social network index & 0.000 & 0.000 & 0.000 & 0.005 & 0.005 & 1.000 & 0.240 \\
\hline $\begin{array}{l}\text { Social } \\
\text { participation }\end{array}$ & Types of activities & 0.000 & 0.000 & 0.000 & 0.004 & 0.004 & 1.000 & 0.220 \\
\hline $\begin{array}{l}\text { Social } \\
\text { participation }\end{array}$ & Participation frequency & 0.002 & 0.000 & 0.002 & 0.007 & 0.007 & 1.000 & 0.360 \\
\hline $\begin{array}{l}\text { Perceived social } \\
\text { isolation }\end{array}$ & $\begin{array}{l}\text { Perceived availability of social } \\
\text { support }\end{array}$ & 0.000 & 0.000 & 0.000 & 0.010 & 0.009 & 1.000 & 0.480 \\
\hline $\begin{array}{l}\text { Perceived social } \\
\text { isolation }\end{array}$ & Felt lonely at least sometimes & 0.003 & 0.000 & 0.003 & 0.006 & 0.006 & 1.000 & 0.310 \\
\hline Intercept & & 0.204 & 0.006 & 0.210 & 0.029 & 0.028 & 0.999 & 1.430 \\
\hline
\end{tabular}


Table 5: Imputation diagnostics for self-reported VD model. In bold, RVI and FMI >0.1, and SE increase of $>10 \%$.

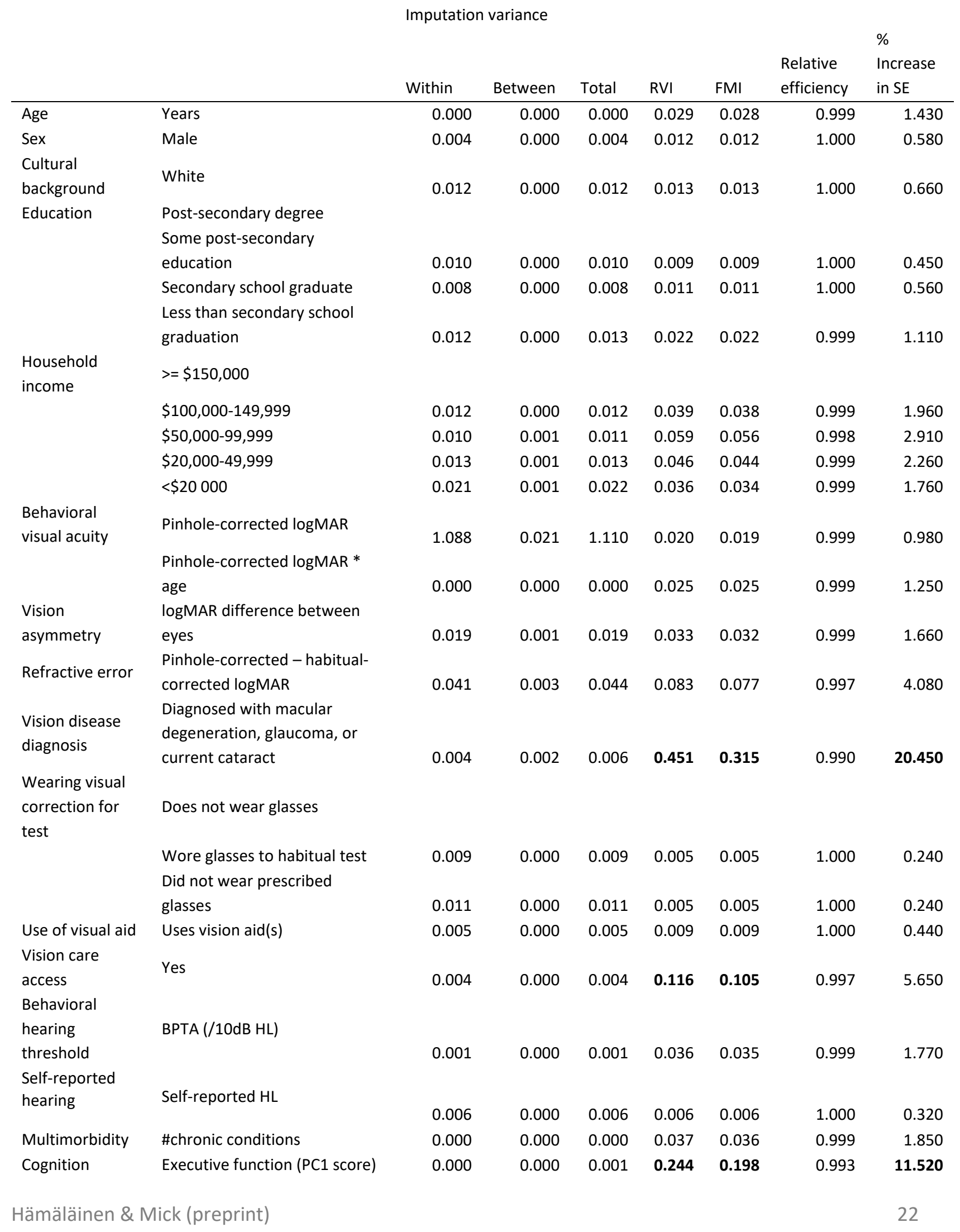




\begin{tabular}{|c|c|c|c|c|c|c|c|c|}
\hline \multirow{4}{*}{$\begin{array}{l}\text { Retirement } \\
\text { status }\end{array}$} & Memory (PC2 score) & 0.001 & 0.000 & 0.001 & 0.197 & 0.166 & 0.994 & 9.410 \\
\hline & Retired & & & & & & & \\
\hline & partly retired & 0.009 & 0.000 & 0.009 & 0.013 & 0.013 & 1.000 & 0.640 \\
\hline & not retired & 0.007 & 0.000 & 0.007 & 0.011 & 0.011 & 1.000 & 0.550 \\
\hline Driving status & Drives at least occasionally & 0.006 & 0.001 & 0.007 & 0.115 & 0.104 & 0.997 & 5.620 \\
\hline Living situation & $\begin{array}{l}\text { Lives alone (ref. lives with } \\
\text { others) }\end{array}$ & 0.005 & 0.000 & 0.005 & 0.011 & 0.011 & 1.000 & 0.560 \\
\hline Life space index & Composite score & 0.000 & 0.000 & 0.000 & 0.014 & 0.014 & 1.000 & 0.710 \\
\hline $\begin{array}{l}\text { Social } \\
\text { participation }\end{array}$ & Social network index & 0.000 & 0.000 & 0.000 & 0.010 & 0.010 & 1.000 & 0.500 \\
\hline $\begin{array}{l}\text { Social } \\
\text { participation }\end{array}$ & Types of activities & 0.001 & 0.000 & 0.001 & 0.007 & 0.007 & 1.000 & 0.370 \\
\hline $\begin{array}{l}\text { Social } \\
\text { participation }\end{array}$ & Participation frequency & 0.003 & 0.000 & 0.003 & 0.008 & 0.008 & 1.000 & 0.410 \\
\hline Perceived social & Perceived availability of social & & & & & & & \\
\hline isolation & support & 0.000 & 0.000 & 0.000 & 0.009 & 0.009 & 1.000 & 0.440 \\
\hline $\begin{array}{l}\text { Perceived social } \\
\text { isolation }\end{array}$ & Felt lonely at least sometimes & 0.004 & 0.000 & 0.004 & 0.006 & 0.006 & 1.000 & 0.290 \\
\hline Intercept & & 0.198 & 0.004 & 0.202 & 0.021 & 0.021 & 0.999 & 1.060 \\
\hline
\end{tabular}

Table 6: Imputation diagnostics for self-reported DSD model. In bold, RVI and FMI $>0.1$, and SE increase of $>10 \%$.

Imputation variance

\begin{tabular}{|c|c|c|c|c|c|c|c|c|}
\hline & & Within & Between & Total & RVI & FMI & $\begin{array}{l}\text { Relative } \\
\text { efficiency }\end{array}$ & $\begin{array}{l}\% \\
\text { Increase } \\
\text { in SE }\end{array}$ \\
\hline Age & Years & 0.000 & 0.000 & 0.000 & 0.032 & 0.031 & 0.999 & 1.610 \\
\hline Sex & Male & 0.013 & 0.000 & 0.013 & 0.018 & 0.017 & 0.999 & 0.880 \\
\hline $\begin{array}{l}\text { Cultural } \\
\text { background }\end{array}$ & White & 0.054 & 0.000 & 0.055 & 0.005 & 0.005 & 1.000 & 0.230 \\
\hline \multirow[t]{4}{*}{ Education } & Post-secondary degree & & & & & & & \\
\hline & Some post-secondary education & 0.033 & 0.000 & 0.033 & 0.005 & 0.005 & 1.000 & 0.230 \\
\hline & Secondary school graduate & 0.026 & 0.000 & 0.026 & 0.006 & 0.005 & 1.000 & 0.270 \\
\hline & $\begin{array}{l}\text { Less than secondary school } \\
\text { graduation }\end{array}$ & 0.029 & 0.000 & 0.030 & 0.014 & 0.014 & 1.000 & 0.720 \\
\hline \multirow{5}{*}{$\begin{array}{l}\text { Household } \\
\text { income }\end{array}$} & $>=\$ 150,000$ & & & & & & & \\
\hline & $\$ 100,000-149,999$ & 0.056 & 0.002 & 0.058 & 0.030 & 0.030 & 0.999 & 1.510 \\
\hline & $\$ 50,000-99,999$ & 0.044 & 0.002 & 0.046 & 0.042 & 0.041 & 0.999 & 2.090 \\
\hline & $\$ 20,000-49,999$ & 0.053 & 0.001 & 0.054 & 0.028 & 0.027 & 0.999 & 1.370 \\
\hline & $<\$ 20,000$ & 0.079 & 0.002 & 0.082 & 0.027 & 0.026 & 0.999 & 1.350 \\
\hline $\begin{array}{l}\text { Behavioral } \\
\text { visual acuity }\end{array}$ & Pinhole-corrected logMAR & 0.082 & 0.004 & 0.086 & 0.048 & 0.046 & 0.998 & 2.390 \\
\hline $\begin{array}{l}\text { Behavioral } \\
\text { hearing } \\
\text { threshold }\end{array}$ & BPTA (/10dB HL) & 0.001 & 0.000 & 0.001 & 0.027 & 0.026 & 0.999 & 1.330 \\
\hline
\end{tabular}




\begin{tabular}{|c|c|c|c|c|c|c|c|c|}
\hline $\begin{array}{l}\text { Vision } \\
\text { asymmetry }\end{array}$ & $\begin{array}{l}\text { logMAR difference between } \\
\text { eyes }\end{array}$ & 0.050 & 0.002 & 0.052 & 0.044 & 0.042 & 0.999 & 2.180 \\
\hline $\begin{array}{l}\text { Hearing } \\
\text { asymmetry }\end{array}$ & $\begin{array}{l}\text { PTA difference between ears } \\
\text { (/10dB HL) }\end{array}$ & 0.005 & 0.000 & 0.005 & 0.060 & 0.057 & 0.998 & 2.950 \\
\hline Use of visual aid & Uses vision aid(s) & 0.017 & 0.000 & 0.017 & 0.004 & 0.004 & 1.000 & 0.200 \\
\hline $\begin{array}{l}\text { Hearing device } \\
\text { user }\end{array}$ & Yes & 0.028 & 0.000 & 0.028 & 0.010 & 0.009 & 1.000 & 0.470 \\
\hline $\begin{array}{l}\text { Trouble hearing } \\
\text { in noise }\end{array}$ & Yes & 0.016 & 0.000 & 0.016 & 0.002 & 0.002 & 1.000 & 0.120 \\
\hline Refractive error & $\begin{array}{l}\text { Pinhole-corrected - habitual- } \\
\text { corrected logMAR }\end{array}$ & 0.150 & 0.013 & 0.163 & 0.087 & 0.080 & 0.997 & 4.250 \\
\hline \multirow{3}{*}{$\begin{array}{l}\text { Wearing visual } \\
\text { correction for } \\
\text { test }\end{array}$} & Does not wear glasses & & & & & & & \\
\hline & Wore glasses to habitual test & 0.033 & 0.000 & 0.033 & 0.002 & 0.002 & 1.000 & 0.120 \\
\hline & Did not wear prescribed glasses & 0.040 & 0.000 & 0.040 & 0.002 & 0.002 & 1.000 & 0.120 \\
\hline $\begin{array}{l}\text { Vision disease } \\
\text { diagnosis }\end{array}$ & $\begin{array}{l}\text { Diagnosed with macular } \\
\text { degeneration, glaucoma, or } \\
\text { current cataract }\end{array}$ & 0.012 & 0.004 & 0.016 & 0.329 & 0.251 & 0.992 & 15.290 \\
\hline $\begin{array}{l}\text { Vision care } \\
\text { access }\end{array}$ & Yes & 0.013 & 0.001 & 0.014 & 0.093 & 0.085 & 0.997 & 4.540 \\
\hline Multimorbidity & \#chronic conditions & 0.001 & 0.000 & 0.001 & 0.070 & 0.066 & 0.998 & 3.440 \\
\hline \multirow[t]{2}{*}{ Cognition } & Executive function (PC1 score) & 0.001 & 0.000 & 0.002 & 0.122 & 0.109 & 0.996 & 5.920 \\
\hline & Memory (PC2 score) & 0.002 & 0.000 & 0.002 & 0.283 & 0.223 & 0.993 & 13.270 \\
\hline \multirow{3}{*}{$\begin{array}{l}\text { Retirement } \\
\text { status }\end{array}$} & Retired & & & & & & & \\
\hline & partly retired & 0.031 & 0.000 & 0.031 & 0.004 & 0.004 & 1.000 & 0.180 \\
\hline & not retired & 0.024 & 0.000 & 0.024 & 0.006 & 0.005 & 1.000 & 0.280 \\
\hline Driving status & Drives at least occasionally & 0.025 & 0.004 & 0.028 & 0.154 & 0.134 & 0.996 & 7.410 \\
\hline Living situation & $\begin{array}{l}\text { Lives alone (ref. lives with } \\
\text { others) }\end{array}$ & 0.018 & 0.000 & 0.018 & 0.004 & 0.004 & 1.000 & 0.200 \\
\hline Life space index & Composite score & 0.000 & 0.000 & 0.000 & 0.010 & 0.010 & 1.000 & 0.520 \\
\hline $\begin{array}{l}\text { Social } \\
\text { participation }\end{array}$ & Social network index & 0.001 & 0.000 & 0.001 & 0.014 & 0.014 & 1.000 & 0.700 \\
\hline $\begin{array}{l}\text { Social } \\
\text { participation }\end{array}$ & Types of activities & 0.003 & 0.000 & 0.003 & 0.003 & 0.003 & 1.000 & 0.140 \\
\hline $\begin{array}{l}\text { Social } \\
\text { participation }\end{array}$ & Participation frequency & 0.010 & 0.000 & 0.010 & 0.002 & 0.002 & 1.000 & 0.110 \\
\hline $\begin{array}{l}\text { Perceived social } \\
\text { isolation }\end{array}$ & $\begin{array}{l}\text { Perceived availability of social } \\
\text { support }\end{array}$ & 0.000 & 0.000 & 0.000 & 0.006 & 0.006 & 1.000 & 0.300 \\
\hline $\begin{array}{l}\text { Perceived social } \\
\text { isolation }\end{array}$ & Felt lonely at least sometimes & 0.015 & 0.000 & 0.015 & 0.008 & 0.008 & 1.000 & 0.410 \\
\hline Intercept & & 0.599 & 0.018 & 0.617 & 0.031 & 0.030 & 0.999 & 1.540 \\
\hline
\end{tabular}


Table 7: Estimates based on models computed within the multiple imputation framework using a set of $M=30$ imputed datasets (resulting $\mathrm{N}=30,097)$ and correcting the estimates for uncertainty resulting from the missing data. Shown are models for self-reported difficulties with hearing (HD), vision (VD), or both hearing and vision (DSD). Statistically significant results in bold.

\begin{tabular}{|c|c|c|c|c|c|c|c|c|c|c|c|c|c|}
\hline & \multicolumn{4}{|c|}{ Self-reported HD } & \multicolumn{4}{|c|}{ Self-reported VD } & \multicolumn{4}{|c|}{ Self-reported DSD } \\
\hline & & OR & SE & $\mathrm{t}$ & $\mathrm{P}$ & OR & SE & $\mathrm{t}$ & $\mathrm{P}$ & OR & SE & $\mathrm{t}$ & $\mathrm{P}$ \\
\hline Age & Years & 0.972 & 0.006 & -4.770 & $<0.001$ & 0.958 & 0.005 & -7.780 & $<0.001$ & 0.958 & 0.007 & -5.750 & $<0.001$ \\
\hline Sex & Male & 1.368 & 0.075 & 5.750 & $<0.001$ & 1.182 & 0.071 & 2.780 & 0.006 & 1.767 & 0.203 & 4.960 & $<0.001$ \\
\hline Cultural background & White & 1.114 & 0.125 & 0.960 & 0.335 & 0.939 & 0.104 & -0.570 & 0.570 & 0.997 & 0.233 & -0.010 & 0.991 \\
\hline Education & Post-secondary degree & Ref. & & & & Ref. & & & & Ref. & & & \\
\hline & $\begin{array}{l}\text { Some post-secondary } \\
\text { education }\end{array}$ & 1.025 & 0.095 & 0.260 & 0.794 & 0.997 & 0.101 & -0.030 & 0.976 & 1.252 & 0.228 & 1.240 & 0.216 \\
\hline & Secondary school graduate & 0.990 & 0.082 & -0.130 & 0.899 & 1.126 & 0.101 & 1.320 & 0.187 & 1.178 & 0.191 & 1.010 & 0.313 \\
\hline Household income & $\begin{array}{l}\text { Less than secondary school } \\
\text { graduation } \\
>=\$ 150,000\end{array}$ & $\begin{array}{l}1.000 \\
\text { Ref. }\end{array}$ & 0.100 & $<0.001$ & 0.997 & $\begin{array}{l}1.260 \\
\text { Ref. }\end{array}$ & 0.142 & 2.060 & 0.040 & $\begin{array}{l}1.248 \\
\text { Ref. }\end{array}$ & 0.216 & 1.280 & 0.200 \\
\hline & $\$ 100,000-149,999$ & 1.142 & 0.102 & 1.490 & 0.136 & 1.422 & 0.156 & 3.200 & 0.001 & 1.233 & 0.300 & 0.860 & 0.389 \\
\hline & $\$ 50,000-99,999$ & 1.144 & 0.093 & 1.650 & 0.100 & 1.669 & 0.171 & 4.990 & $<0.001$ & 1.652 & 0.358 & 2.320 & 0.020 \\
\hline & $\$ 20,000-49,999$ & 1.096 & 0.102 & 0.980 & 0.326 & 2.021 & 0.235 & 6.050 & $<0.001$ & 1.732 & 0.411 & 2.310 & 0.021 \\
\hline & $<\$ 20,000$ & 1.047 & 0.146 & 0.330 & 0.743 & 2.172 & 0.327 & 5.150 & $<0.001$ & 1.709 & 0.497 & 1.840 & 0.065 \\
\hline Behavioral hearing & BPTA (/10dB HL) & & & & & & & & & & & & \\
\hline threshold & & 2.291 & 0.284 & 6.700 & $<0.001$ & 0.890 & 0.024 & -4.330 & $<0.001$ & 1.369 & 0.052 & 8.200 & $<0.001$ \\
\hline $\begin{array}{l}\text { Self-reported } \\
\text { hearing }\end{array}$ & Self-reported HD & & & & & 2.922 & 0.223 & 14.030 & $<0.001$ & & & & \\
\hline BPTA * age & Interaction & 0.998 & 0.002 & -1.380 & 0.166 & & & & & & & & \\
\hline Hearing asymmetry & $\begin{array}{l}\text { PTA difference between } \\
\text { ears (/10dB HL) }\end{array}$ & 1.556 & 0.054 & 12.670 & $<0.001$ & & & & & 1.209 & 0.086 & 2.660 & 0.008 \\
\hline Hearing device user & Yes & 0.763 & 0.072 & -2.890 & 0.004 & & & & & 0.959 & 0.163 & -0.250 & 0.805 \\
\hline $\begin{array}{l}\text { Trouble hearing in } \\
\text { noise }\end{array}$ & Yes & 6.267 & 0.354 & 32.510 & $<0.001$ & & & & & 4.144 & 0.529 & 11.130 & $<0.001$ \\
\hline $\begin{array}{l}\text { Behavioral visual } \\
\text { acuity }\end{array}$ & Pinhole-corrected logMAR & 0.900 & 0.161 & -0.590 & 0.557 & 16.139 & 16.958 & 2.650 & 0.008 & 10.589 & 3.142 & 7.950 & $<0.001$ \\
\hline Self-reported vision & Self-reported VD & 2.723 & 0.212 & 12.880 & $<0.001$ & & & & & & & & \\
\hline Vision asymmetry & $\begin{array}{l}\text { logMAR difference } \\
\text { between eyes }\end{array}$ & & & & & 6.393 & 0.881 & 13.470 & $<0.001$ & 3.193 & 0.724 & 5.120 & $<0.001$ \\
\hline $\begin{array}{l}\text { Pinhole-corrected } \\
\text { logMAR * age }\end{array}$ & Interaction & & & & & 1.022 & 0.016 & 1.360 & 0.173 & & & & \\
\hline
\end{tabular}




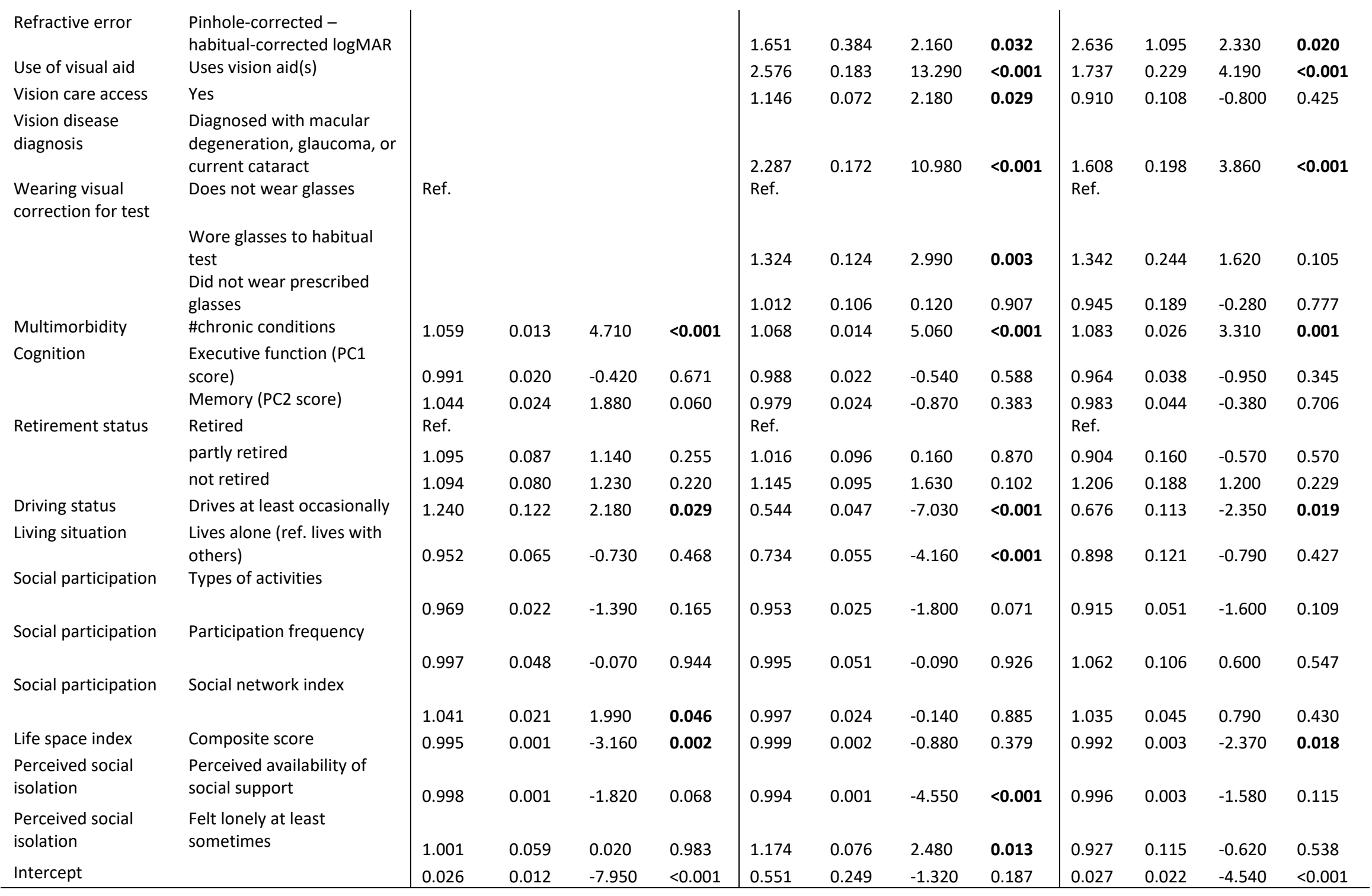


Table 8: Estimates based on complete-case models of self-reported difficulties with hearing (HD, $N=17,802)$, vision (VD, $N=11,610)$, or both hearing and vision (DSD, $N=11,292$ ). Statistically significant results in bold.

\begin{tabular}{|c|c|c|c|c|c|c|c|c|c|c|c|c|c|}
\hline & & \multicolumn{4}{|c|}{ Self-reported HD } & \multicolumn{4}{|c|}{ Self-reported VD } & \multicolumn{4}{|c|}{ Self-reported DSD } \\
\hline & & OR & SE & $\mathrm{t}$ & $\mathrm{P}$ & OR & SE & $\mathrm{t}$ & $\mathrm{P}$ & OR & SE & $\mathrm{t}$ & $\mathrm{P}$ \\
\hline Age & Years & 0.970 & 0.008 & -3.750 & $<0.001$ & 0.943 & 0.009 & -5.900 & $<0.001$ & 0.957 & 0.015 & -2.840 & 0.005 \\
\hline Sex & Male & 1.513 & 0.113 & 5.530 & $<0.001$ & 1.282 & 0.132 & 2.420 & 0.015 & 2.568 & 0.592 & 4.090 & $<0.001$ \\
\hline Cultural background & White & 0.995 & 0.150 & -0.030 & 0.973 & 1.118 & 0.229 & 0.540 & 0.587 & 0.801 & 0.347 & -0.510 & 0.608 \\
\hline \multirow[t]{4}{*}{ Education } & Post-secondary degree & Ref. & & & & & & & & & & & \\
\hline & $\begin{array}{l}\text { Some post-secondary } \\
\text { education }\end{array}$ & 1.118 & 0.143 & 0.870 & 0.385 & 0.857 & 0.160 & -0.830 & 0.409 & 1.059 & 0.447 & 0.140 & 0.892 \\
\hline & Secondary school graduate & 0.897 & 0.111 & -0.870 & 0.383 & 0.897 & 0.148 & -0.660 & 0.510 & 1.034 & 0.341 & 0.100 & 0.918 \\
\hline & $\begin{array}{l}\text { Less than secondary school } \\
\text { graduation }\end{array}$ & 0.998 & 0.148 & -0.020 & 0.988 & 1.066 & 0.247 & 0.280 & 0.782 & 1.036 & 0.394 & 0.090 & 0.925 \\
\hline \multirow[t]{5}{*}{ Household income } & $>=\$ 150,000$ & Ref. & & & & & & & & & & & \\
\hline & $\$ 100,000-149,999$ & 1.160 & 0.130 & 1.330 & 0.185 & 1.481 & 0.255 & 2.280 & 0.023 & 1.057 & 0.420 & 0.140 & 0.889 \\
\hline & $\$ 50,000-99,999$ & 1.190 & 0.125 & 1.660 & 0.098 & 1.548 & 0.255 & 2.650 & 0.008 & 1.134 & 0.401 & 0.360 & 0.722 \\
\hline & $\$ 20,000-49,999$ & 1.174 & 0.144 & 1.310 & 0.191 & 2.191 & 0.416 & 4.130 & $<0.001$ & 1.559 & 0.644 & 1.070 & 0.282 \\
\hline & $<\$ 20,000$ & 1.073 & 0.214 & 0.350 & 0.725 & 3.063 & 0.771 & 4.450 & $<0.001$ & 1.540 & 0.838 & 0.790 & 0.427 \\
\hline $\begin{array}{l}\text { Behavioral hearing } \\
\text { threshold }\end{array}$ & BPTA (/10dB HL) & 2.299 & 0.412 & 4.640 & $<0.001$ & 0.907 & 0.041 & -2.150 & 0.032 & 1.468 & 0.100 & 5.610 & $<0.001$ \\
\hline $\begin{array}{l}\text { Self-reported } \\
\text { hearing }\end{array}$ & Self-reported HD & & & & & 3.087 & 0.421 & 8.260 & $<0.001$ & & & & \\
\hline BPTA * age & Interaction & 0.998 & 0.003 & -0.820 & 0.414 & & & & & & & & \\
\hline Hearing asymmetry & $\begin{array}{l}\text { PTA difference between } \\
\text { ears (/10dB HL) }\end{array}$ & 1.578 & 0.072 & 9.960 & $<0.001$ & & & & & 1.242 & 0.151 & 1.780 & 0.076 \\
\hline Hearing device user & Yes & 0.727 & 0.097 & -2.390 & 0.017 & & & & & 0.549 & 0.231 & -1.430 & 0.154 \\
\hline $\begin{array}{l}\text { Trouble hearing in } \\
\text { noise }\end{array}$ & Yes & 6.727 & 0.522 & 24.550 & $<0.001$ & & & & & 4.753 & 1.166 & 6.360 & $<0.001$ \\
\hline $\begin{array}{l}\text { Behavioral visual } \\
\text { acuity }\end{array}$ & Pinhole-corrected logMAR & 1.329 & 0.331 & 1.140 & 0.253 & 0.918 & 1.766 & -0.040 & 0.965 & 36.550 & 24.109 & 5.460 & $<0.001$ \\
\hline Self-reported vision & Self-reported VD & 2.661 & 0.295 & 8.820 & $<0.001$ & & & & & & & & \\
\hline Vision asymmetry & $\begin{array}{l}\text { logMAR difference } \\
\text { between eyes }\end{array}$ & & & & & 6.775 & 1.513 & 8.570 & $<0.001$ & 2.135 & 1.017 & 1.590 & 0.111 \\
\hline $\begin{array}{l}\text { Pinhole-corrected } \\
\text { logMAR * age }\end{array}$ & Interaction & & & & & 1.074 & 0.033 & 2.350 & 0.019 & & & & \\
\hline Refractive error & $\begin{array}{l}\text { Pinhole-corrected - } \\
\text { habitual-corrected logMAR }\end{array}$ & & & & & 1.181 & 0.441 & 0.450 & 0.656 & 1.154 & 0.868 & 0.190 & 0.849 \\
\hline
\end{tabular}




\begin{tabular}{|c|c|c|c|c|c|c|c|c|c|c|c|c|c|}
\hline Use of visual aid & Uses vision aid(s) & & & & & 2.158 & 0.274 & 6.060 & $<0.001$ & 1.991 & 0.467 & 2.940 & 0.003 \\
\hline Vision care access & Yes & & & & & 1.010 & 0.102 & 0.100 & 0.923 & 0.733 & 0.153 & -1.490 & 0.137 \\
\hline $\begin{array}{l}\text { Vision disease } \\
\text { diagnosis }\end{array}$ & $\begin{array}{l}\text { Diagnosed with macular } \\
\text { degeneration, glaucoma, or } \\
\text { current cataract }\end{array}$ & & & & & 2.029 & 0.251 & 5.710 & $<0.001$ & 1.415 & 0.302 & 1.630 & 0.103 \\
\hline \multirow{3}{*}{$\begin{array}{l}\text { Wearing visual } \\
\text { correction for test }\end{array}$} & Does not wear glasses & & & & & Ref. & & & & & & & \\
\hline & $\begin{array}{l}\text { Wore glasses to habitual } \\
\text { test }\end{array}$ & & & & & 1.190 & 0.181 & 1.150 & 0.252 & 1.114 & 0.342 & 0.350 & 0.724 \\
\hline & $\begin{array}{l}\text { Did not wear prescribed } \\
\text { glasses }\end{array}$ & & & & & 0.824 & 0.142 & -1.120 & 0.263 & 0.684 & 0.243 & -1.070 & 0.285 \\
\hline Multimorbidity & \#chronic conditions & 1.058 & 0.018 & 3.350 & 0.001 & 1.088 & 0.024 & 3.790 & $<0.001$ & 1.085 & 0.060 & 1.490 & 0.137 \\
\hline \multirow[t]{2}{*}{ Cognition } & $\begin{array}{l}\text { Executive function (PC1 } \\
\text { score) }\end{array}$ & 1.008 & 0.027 & 0.290 & 0.774 & 0.956 & 0.038 & -1.140 & 0.254 & 0.896 & 0.069 & -1.410 & 0.158 \\
\hline & Memory (PC2 score) & 1.077 & 0.030 & 2.680 & 0.007 & 1.001 & 0.042 & 0.020 & 0.981 & 1.047 & 0.088 & 0.550 & 0.580 \\
\hline \multirow[t]{3}{*}{ Retirement status } & Retired & Ref. & & & & & & & & & & & \\
\hline & partly retired & 1.202 & 0.127 & 1.730 & 0.083 & 0.818 & 0.147 & -1.120 & 0.262 & 0.773 & 0.282 & -0.710 & 0.480 \\
\hline & not retired & 1.162 & 0.115 & 1.520 & 0.130 & 0.955 & 0.145 & -0.300 & 0.761 & 1.142 & 0.360 & 0.420 & 0.674 \\
\hline Driving status & Drives at least occasionally & 1.483 & 0.212 & 2.750 & 0.006 & 0.641 & 0.094 & -3.020 & 0.003 & 0.732 & 0.258 & -0.880 & 0.376 \\
\hline Living situation & $\begin{array}{l}\text { Lives alone (ref. lives with } \\
\text { others) }\end{array}$ & 1.032 & 0.099 & 0.330 & 0.740 & 0.729 & 0.100 & -2.310 & 0.021 & 1.220 & 0.303 & 0.800 & 0.423 \\
\hline Social participation & Types of activities & 0.942 & 0.029 & -1.920 & 0.055 & 0.958 & 0.045 & -0.920 & 0.355 & 0.800 & 0.088 & -2.040 & 0.042 \\
\hline Social participation & Participation frequency & 1.009 & 0.069 & 0.140 & 0.890 & 1.022 & 0.094 & 0.230 & 0.814 & 1.221 & 0.265 & 0.920 & 0.356 \\
\hline Social participation & Social network index & 1.043 & 0.029 & 1.520 & 0.128 & 0.981 & 0.044 & -0.430 & 0.667 & 1.047 & 0.086 & 0.560 & 0.575 \\
\hline Life space index & Composite score & 0.995 & 0.002 & -2.300 & 0.021 & 1.000 & 0.003 & -0.110 & 0.916 & 1.005 & 0.007 & 0.730 & 0.466 \\
\hline $\begin{array}{l}\text { Perceived social } \\
\text { isolation }\end{array}$ & $\begin{array}{l}\text { Perceived availability of } \\
\text { social support }\end{array}$ & 0.997 & 0.002 & -1.660 & 0.096 & 0.992 & 0.002 & -3.480 & 0.001 & 0.993 & 0.005 & -1.350 & 0.177 \\
\hline $\begin{array}{l}\text { Perceived social } \\
\text { isolation }\end{array}$ & $\begin{array}{l}\text { Felt lonely at least } \\
\text { sometimes }\end{array}$ & 0.948 & 0.079 & -0.650 & 0.518 & 1.223 & 0.136 & 1.810 & 0.070 & 0.782 & 0.188 & -1.030 & 0.305 \\
\hline Intercept & & 0.019 & 0.012 & -6.320 & 0.000 & 1.344 & 1.074 & 0.370 & 0.712 & 0.010 & 0.017 & -2.720 & 0.007 \\
\hline
\end{tabular}




\section{Conclusions}

We have described a two-step approach that permits the inclusion of cases with missing data in variables included in data reduction analyses as part of broad regression analyses. As might be predicted, variables with the highest amount of missing data provided results with somewhat lower degree of reliability, but based on the range of diagnostics we performed, this did not influence the qualitative outcome of our models. This indicates that, with the large number of correlated variables collected by the CLSA from a large number of participants, a multiple imputation approach that employs chained equations is useful and likely surpasses complete-case analyses in predictive value. This is especially important for future sweeps when the proportion of participants with missing data may further increase in a non-random way as a result of an aging study population and possible participation fatigue. We therefore recommend that CLSA researchers and others examining large epidemiological datasets to carefully consider the multiple imputation approaches they employ, when appropriate imputing sets of variables in sequence as we have done.

\section{Acknowledgments}

This research was made possible using data/biospecimens collected by the Canadian Longitudinal Study on Aging (CLSA). Funding for CLSA is provided by the Government of Canada through the Canadian Institutes of Health Research (CIHR) under grant reference: LSA 9447 and the Canada Foundation for Innovation. This research has been conducted using the CLSA Baseline Comprehensive dataset version 3.2, under Application Number 160605. The CLSA is led by Drs. Parminder Raina, Christina Wolfson, and Susan Kirkland. This work is part of the Canadian Consortium on Neurodegeneration in Aging (project team 17), which is supported by a grant from the Canadian Institute of Health Research with funding from several partners. Funding for the present research was provided by a CIHR Catalyst grant (ACD151277) and the Réseau Québécois de Recherche sur le Vieillissement (RQRV). The present project received ethics approval by the University of British Columbia (\#H15-00430) and the University of Montreal (\#17-063-CERES-D). We thank Biljana Stojkova for help with designing the multiple imputation approach. The research reported here is part of the work of the CCNA team 17, in particular Margaret $\mathrm{K}$. Pichora-Fuller, Walter Wittich, and Natalie Phillips.

\section{References}

1. UCLA Statistical Consulting Group. Multiple Imputation in Stata. Available at: https://stats.idre.ucla.edu/stata/seminars/mi_in_stata_pt1_new/. (Accessed: 8th August 2019)

2. Royston, P. \& White, I. Multiple Imputation by Chained Equations (MICE): Implementation in Stata. J. Stat. Softw. 45, 1-20 (2011).

3. Buuren, S. van \& Groothuis-oudshoorn, K. MICE : Multivariate Imputation by Chained Equations 
in R. J. Stat. Softw. VV, 1-68 (2010).

4. White, I. R., Royston, P. \& Wood, A. M. Multiple imputation using chained equations: Issues and guidance for practice. Stat. Med. 30, 377-399 (2011).

5. Azur, M. J., Stuart, E. A., Frangakis, C. \& Leaf, P. J. Multiple Imputation by Chained Equations: What is it and how does it work? Int J Methods Psychiatr Res 20, 40-49 (2011).

6. Sterne, J. A. C. et al. Multiple imputation for missing data in epidemiological and clinical research: potential and pitfalls. BMJ 338, 1-12 (2009).

7. von Hippel, P. T. How To Impute Squares, Interactions, and Other Transformed Variables. Sociol. Methodol. 39, 265-291 (2009).

8. Truxillo, C. Maximum likelihood parameter estimation with incomplete data. Proc. Thirtieth Annu. SAS ${ }^{\circledR}$ Users Gr. 1-19 (2005).

9. Graham, J. W. Missing Data Analysis: Making It Work in the Real World. Annu. Rev. Psychol. 60, 549-576 (2009).

10. Weaver, B. \& Maxwell, H. Exploratory factor analysis and reliability analysis with missing data: A simple method for SPSS users. Quant. Methods Psychol. 10, 143-152 (2014).

11. Schafer, J. L. Analysis of Incomplete Multivariate Data. (Chapman and Hall/CRC, 1997).

12. Hämäläinen, A., Phillips, N., Wittich, W., Pichora-Fuller, M. K. \& Mick, P. Do social factors mediate or moderate the sensory-cognitive associations in older adults in the Canadian Longitudinal Study on Aging ? PsyArXiv (2019). doi:10.31234/osf.io/y8mh9

13. Phillips, N., Hämäläinen, A., Wittich, W., Pichora-Fuller, M. K. \& Mick, P. Associations between cognitive and sensory function in older adults: a snapshot of the first wave of the Canadian Longitudinal Study of Aging (CLSA). in prep.

14. Hämäläinen, A., Pichora-Fuller, M. K., Wittich, W., Phillips, N. \& Mick, P. Self-report Measures of Hearing and Vision in Older Adults Participating in the Canadian Longitudinal Study of Aging are Explained by Behavioral Sensory Measures, Demographic and Social Factors. PsyArXiv (2019). doi:10.31234/osf.io/58eqg

15. Raina, P., Wolfson, C. \& Kirkland, S. The Canadian Longitudinal Study on Aging (CLSA) Report on Health and Aging in Canada: Findings from Baseline Data Collection 2010-2015. Prepared for the Canadian Institutes for Health Research and the Government of Canada, August 2018. (2018).

16. Raina, P. S. et al. The Canadian Longitudinal Study on Aging (CLSA). Can. J. Aging 28, 221-229 (2009).

17. Tuokko, H., Griffith, L. E., Simard, M. \& Taler, V. Cognitive measures in the Canadian Longitudinal Study on Aging. Clin. Neuropsychol. 31, 233-250 (2017).

18. Raina, P. et al. Cohort profile: The Canadian Longitudinal Study on Aging (CLSA). Int. J. Epidemiol. 1-12 (2019). doi:10.1093/ije/dyz173

19. Tuokko, H., Griffith, L. E., Simard, M. \& Taler, V. Cognitive measures in the Canadian Longitudinal Study on Aging. Clin. Neuropsychol. 31, 233-250 (2017).

20. Mick, P., Hämäläinen, A., Pichora-Fuller, M. K., Phillips, N. A. \& Wittich, W. Evaluation of how well 
different pure-tone threshold and visual acuity measures reflect self- reported sensory ability and treatment uptake: An analysis of the Canadian Longitudinal Study on Aging Paul. PsyArXiv (2019). doi:10.31234/osf.io/f8rnc

21. Mick, P. et al. The prevalence of hearing and vision loss in older Canadians: An analysis of Data from the Canadian Longitudinal Study on Aging. PsyArXiv (2019). doi:10.31234/osf.io/v7kr5

22. StataCorp LLC. Stata multiple-imputation reference manual. (2017).

23. Buuren, S. Van. Multiple imputation of discrete and continuous data by fully conditional specification. Stat. Methods Med. Res. 16, 219-242 (2007).

24. Rubin, D. B. Multiple Imputation for Nonresponse in Surveys. Journal of Marketing Research 26, (J. Wiley \& Sons, 1989).

25. Nguyen, C. D., Carlin, J. B. \& Lee, K. J. Model checking in multiple imputation: an overview and case study. Emerg. Themes Epidemiol. 1-12 (2017). doi:10.1186/s12982-017-0062-6

26. Abayomi, K., Gelman, A. \& Levy, M. Diagnostics for Multivariate Imputations. J. R. Stat. Soc. Ser. C (Applied Stat. 57, 273-291 (2008). 


\section{Appendix: Stata code}

Table S1: Variable names used in the Stata code in this Appendix.

\begin{tabular}{|c|c|}
\hline Variable & Variable name \\
\hline Rey Auditory Verbal Learning Test, Delayed recall & rey2 \\
\hline Rey Auditory Verbal Learning Test, Recall ratio & reyratio \\
\hline Stroop test, Interference task & stp \\
\hline Stroop ratio, Stroop ratio & stpratio \\
\hline Mental alternation test & mat \\
\hline Controlled Oral Word Association Test & fas \\
\hline Animal fluency test & aft \\
\hline \multicolumn{2}{|l|}{ Variables of interest (included in estimation models) } \\
\hline Age ( $45-85$ years) & age \\
\hline Sex & sex \\
\hline BPTA (mid-range, $10 \mathrm{~dB} \mathrm{HL}$ ) & bpta10_mid \\
\hline Pinhole VA logMAR & logmar_phb \\
\hline Self-report hearing difficulty (HD) & self_hd \\
\hline Self-report vision difficulty (VD) & self_vd \\
\hline Ear asymmetry & ptadif10 \\
\hline Eye asymmetry & logmarphdif \\
\hline Better-eye refractive error & va_ref_b \\
\hline Trouble hearing in noise & hrgnoise \\
\hline Vision pathology diagnosis & vis_diag \\
\hline Visited eye care professional & opto \\
\hline Wore prescribed vision correction for test & va_wear \\
\hline Vision aid use & logitvisaid \\
\hline Hearing aid use & logithrgdev \\
\hline PC1 (Executive function) ${ }^{2}$ & pc1 \\
\hline PC2 (Memory) ${ }^{2}$ & pc2 \\
\hline Multimorbidity & morbid \\
\hline Cultural background & white \\
\hline Education & edrev \\
\hline Income & increv \\
\hline Life space index & Isc \\
\hline Social participation types & $\mathrm{sp}$ \\
\hline Social network index & sni \\
\hline Social support availability & ss \\
\hline Social participation frequency & sp_freq \\
\hline Retirement status & retired \\
\hline Driving status & drive_bin \\
\hline Lives alone & livealone \\
\hline Feeling lonely & lonely_bin \\
\hline
\end{tabular}




\section{Auxiliary variables used to improve imputations}

BPTA “Low frequencies”

bpta_lo

BPTA "Speech frequencies"

bpta_sp

BPTA "High frequencies"

bpta_hi

Binocular habitual visual acuity

logmarrl

Stroop test baseline time ("dot time")

stp_dottime

Wants more social participation

sp_wantmore

Passive variable created from imputed variables

Dual sensory difficulty (VD+HD)

self_dual_mi

\section{$* * * * * * * * *$}

\section{* FORMAT DATA}

* Assign survey design, setting population weights to CLSA-provided variable wta svyset $[p w=w t a]$

* Set data as mi to permit multiple imputations, choosing the "wide" data format mi set wide

\section{* MULTIPLE IMPUTATION STEP 1}

$* * * * * * * * *$

\section{* IMPUTE COGNITIVE DATA FOR PCA}

* Use all available cognitive data to calculate PCA for cases without missing cognitive data

* Use the mvn method to generate an expectation-maximization matrix (em)

* Set seed for reproducibility

mi impute mvn rey2 reyratio stp stpratio mat fas aft1, emonly rseed(123)

*Generate and view covariance matrix

* see https://www.stata.com/statalist/archive/2010-07/msg01382.html

matrix cov_em $=$ r(Sigma_em $)$ 
* Print the matrix

matrix list cov_em

* Compute PCA based on a correlation matrix (standardized covariance matrix created above)

* Set $\mathrm{N}$ as the number of non-missing cases for the cognitive variable with the highest \# missing (mat) pcamat cov_em, $\mathrm{n}(27666)$ cor

* Conduct varimax-rotation of the two primary principal components

* For convenience, mark loadings $<0.2$ as blank

rotate, varimax normalize blanks(.2) comp(2)

* Derive composite cognitive scores as pc1 an pc2 based on the rotated PCA weighting factors

* Computed for those people with no missing data in the raw cognitive variables

predict pc1 pc2, score

* STEP 1 DIAGNOSTICS

* Following https://stats.idre.ucla.edu/stata/seminars/mi_in_stata_pt1_new/

* Running a Markov Chain Monte Carlo (MCMC) algorithm only to impute missing values for each variable without storing new data sets.

* Burn in-value of 1000 indicates that 1000 iterations are performed, equivalent to 10 datasets

* Save information on the iterations into a "trace" (here called trace1) to examine MCMC convergence mi impute mvn rey2 reyratio stp stpratio mat fas aft $1, / / /$

mcmconly burnin(1000) rseed(123) saveptrace(trace1, replace)

* Use the command ptrace to access and examine the saved trace data

mi ptrace use trace1, clear

describe 
* Set the iteration data as a time series to graph the coefficients and variances against iteration number tsset iter

* Draw trace plots to examine convergence. Examine plots for longitudinal patterns (flat areas) which indicate slow convergences - here, no such problems were detected (Figure 2).

* Use the arbitrary variables names $\left(b_{-} \ldots v_{-} \ldots\right)$ that were generated by ptrace describe above for coefficient constant, variance and covariance

tsline b_y7x1, name(mice1,replace)legend(off) ytitle("AFT constant")

tsline v_y5y5, name(mice1,replace)legend(off) ytitle("MAT variance")

tsline v_y5y5, name(mice1,replace)legend(off) ytitle("AFT-MAT covariance")

* Draw autocorrelation plots based on the "worst linear function" WLF with similar criteria as above

* WLF combines information from several variables with the highest fraction of missing information

mi impute mvn rey2 reyratio stp stpratio mat fas aft1, ///

momconly burnin(1000) rseed(123) savewlf(wlf)

use wlf, clear

describe

* Set iteration number as a time series to plot wlf autocorrelation diagnostics (Figure 3)

tsset iter

tsline wlf, ytitle(Worst linear function) xtitle(Burn-in period)

ac wlf, title(Worst linear function) ytitle (Autocorrelations)

ciopts(astyle(none)) note(" ")

* STEP 2 GLOBAL MULTIPLE IMPUTATIONS

* REGISTER VARIABLES 
* Register all variables used in imputation (variables of interest \& auxiliary)

* No missing data for age and sex -> register as "regular"

mi register regular age sex

* Register all other variables of interest and auxiliary variables as imputed (different lines for organizational purposes)

mi register imputed edrev increv white morbid

mi register imputed bpta_sp bpta10_mid bpta_lo bpta_hi wpta ptadif10

mi register imputed logithrgdev hrg hrgnoise

mi register imputed logmarrl logmar_phb logmarphdif va_ref_b

mi register imputed logitvisaid vis_diag vis opto va_wear

mi register imputed Isc ss sp sp_freq lonely_bin sni sp_wantmore

mi register imputed retired drive_bin livealone

mi register imputed self_hd self_vd

mi register imputed pc1 pc2

* Create passive variable for dual sensory difficulty from imputed variables self-reported hearing \& vision difficulties (used as the response variable in models of dual sensory difficulty, DSD)

mi passive: gen self_dual_mi=.

mi passive: replace self_dual_mi $=0$ if (self_vd==0 | self_hd $==0$ )

mi passive: replace self_dual_mi= 1 if (self_vd $==1 \&$ self_hd $==1$ )

la def self_dual_mi 0 "No self-reported DSL" 1 "Self-reported DSL"

la val self_dual_mi self_dual_mi

la var self_dual_mi "Self-reported dual sensory loss"

\section{* EXAMINE MISSING DATA}

* Tabulate missing data for all variables used in imputations 
graph combine logmar_phb bpta10_mid self_hd self_vd, title(Trace plots of summaries of imputed values) rows(2)

* trace plots (examples for the variables with the most missing data; Figure 5)

tsline pc1_mean, name(pc1) nodraw

tsline pc2_mean, name(pc2) nodraw

tsline vis_diag_mean, name(vis_diag) nodraw

tsline va_ref_b_mean, name(va_ref_b) nodraw

graph combine pc1 pc2 vis_diag va_ref_b, title(Trace plots of summaries of imputed values) rows(2)

\section{* Autocorrelation plots examples; Figure 6}

ac logmar_phb_mean, ciopts(astyle(none)) ytitle("") xtitle("") title(Pinhole-corrected logMAR) note("") name(ac1, replace) lags(100) nodraw

ac bpta10_mid_mean, ciopts(astyle(none)) ytitle("") xtitle("") title(BPTA (10 dB HL)) note("") name(ac2, replace) lags(100) nodraw

ac self_vd_mean, ciopts(astyle(none)) ytitle("") xtitle("") title(Self-reported VD) note("") name(ac3, replace) lags(100) nodraw

ac self_hd_mean, ciopts(astyle(none)) ytitle("") xtitle("") title(Self-reported HD) note(") name(ac4, replace) lags(100) nodraw

ac pc1_mean, ciopts(astyle(none)) ytitle("") xtitle("") title(Cognition PC1) note("") name(ac5, replace) lags(100) nodraw

ac pc2_mean, ciopts(astyle(none)) ytitle("") xtitle("") title(Cognition PC2) note("") name(ac6, replace) lags(100) nodraw

ac vis_diag_mean, ciopts(astyle(none)) ytitle("") xtitle("") title(Vision disease diagnosis) note("") name(ac7, replace) lags(100) nodraw

ac va_ref_b_mean, ciopts(astyle(none)) ytitle("") xtitle("") title(Better-eye refractive error) note("") name(ac8, replace) lags(100) nodraw

\section{* Combine plots}


graph combine ac1 ac2 ac3 ac4 ac5 ac6 ac7 ac8, xcommon cols(4) title(Autocorrelation plots) b1(Lag) I1(Autocorrelations (r))

\section{* RUN CHAINED EQUATIONS}

* Conduct chained equations multiple imputation (MICE)

* Full model imputation for $\mathrm{M}=30$ datasets

* Note that here we also impute pc-scores for people with missing cognitive data

$* \operatorname{add}(30)=$ create 30 imputed datasets

* rseed $(123)$ = set seed for reproducibility

mi impute chained ///

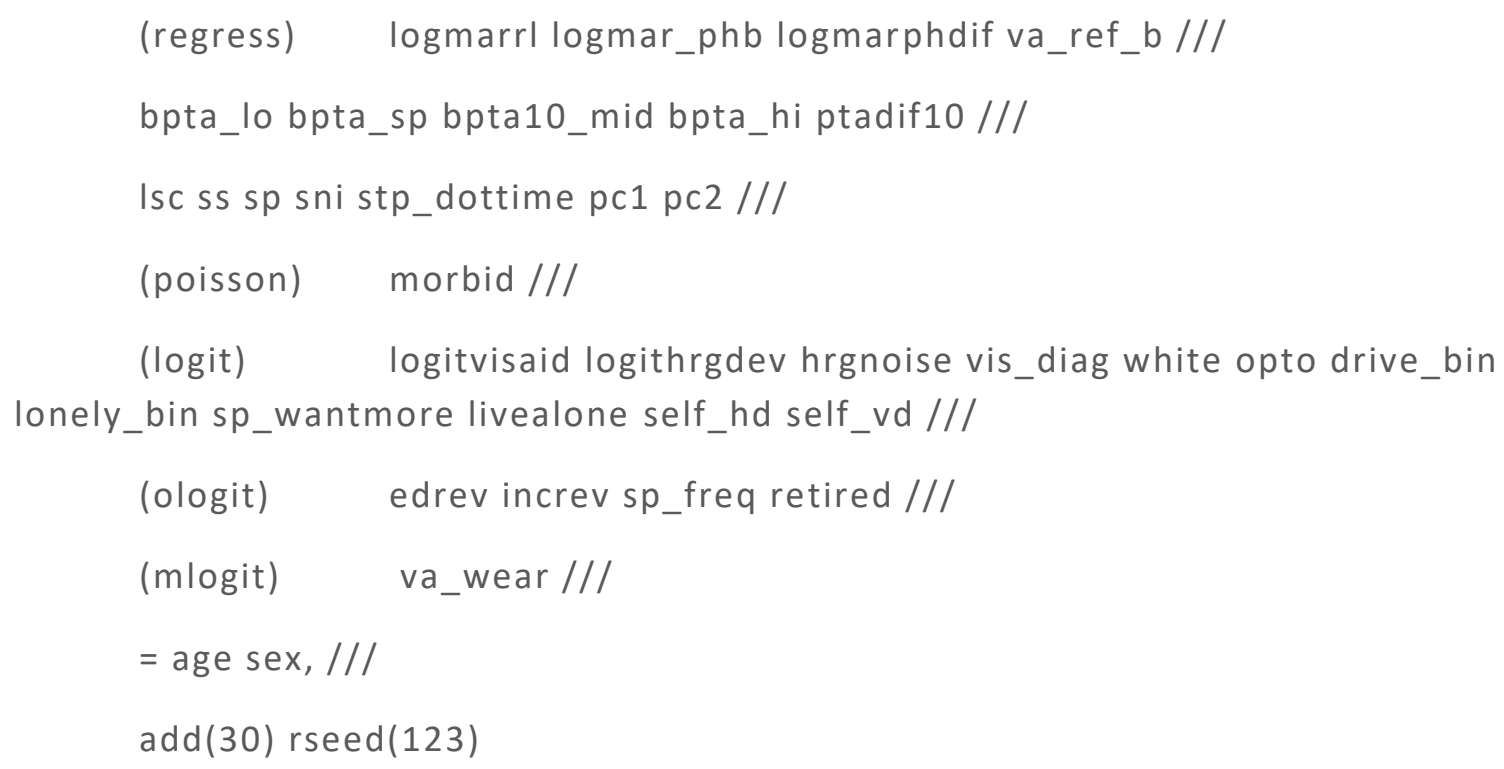

* save imputed datasets

save "C:\[...]\IMPUTED_all.dta", replace

\section{* STEP 2 DIAGNOSTICS, PART B}


* Optional: clear and reload data

clear

use "C:\[...]\IMPUTED_all.dta", replace

* Example data examination: inspect pc1 and pc2 scores for all datasets

mi xeq: summ pc1 pc2

* Diagnostic plots for each of the 30 imputations

* Time consuming; here printing only datasets 1-5 for pc1

midiagplots pc1, $\mathrm{m}(1 / 5)$ combine example using $\mathrm{pc} 1$, plot all 30 graphs in the same window

* Test whether observed \& imputed data are statistically significantly different midiagplots pc1, nograph ksmirnov

* MI MODEL ESTIMATION

* EXAMPLE: FULL MODEL FOR HD

* Model is run in the mi framework with mi estimate.

* Specify svy to use survey design; logistic to indicate the response variable is binomial.

* c. indicates continuous variable, i. a categorical variable; these may prevent errors especially for interaction terms

* Optional: specify or to print odds ratios instead of Beta-values

mi estimate, or: svy: logistic self_hd c.bpta10_mid\#\#c.age c.ptadif10 i.logithrgdev

i.hrgnoise i.edrev i.increv i.sex i.white ///

c.logmar_phb i.self_vd c.morbid c.pc1 c.pc2 ///

i.retired i.drive_bin i.livealone c.sp sp_freq c.sni c.Isc c.ss i.lonely_bin 
$* * * * * * * * * * * * * * * * * * * * * * * * * * * * * * * *$

* MODEL ESTIMATION DIAGNOSTICS

* Derive diagnostics for effects of imputed data on model estimates

mi estimate, or vartable dftable

$* * * * * * * * * * * * * * * * * * * * * * * * * * * * * * * *$

* COMPLETE CASE ANALYSIS

* Run a complete-case model using the same model structure as above for the imputed model, but limiting the analysis to dataset 0 , i.e. original unimputed data

mi xeq 0: svy: logistic self_hd c.bpta10_mid\#\#c.age c.ptadif10 i.logithrgdev i.hrgnoise i.edrev i.increv i.sex i.white ///

c.logmar_phbi.self_vd morbid pc1 pc2 ///

i.retired i.drive_bin i.livealone sp sp_freq sni Isc ss i.lonely_bin 